\title{
Should Oscar Pistorius be Allowed to Compete at the Olympic Games?
}

By

\section{Terence Davidson}

A thesis submitted to Victoria University of Wellington

in fulfilment of the requirements for the degree

of Master of Arts in Philosophy

Victoria University of Wellington 


\section{Acknowledgements}

Thank you to everyone who has taken the time to discuss my thesis with me. From best friends to strangers in bars, you know who you are. Particular thanks to Nick Agar for his supervision, and everyone in the Victoria University of Wellington Philosophy department for indulging me in my love of sport. Most importantly thank you to Mum, Dad, and Agata. 


\section{Abstract}

On the $4^{\text {th }}$ of August 2012 South African runner Oscar Pistorius became the first athlete to compete at the Olympic Games while running on prosthetic limbs. Pistorius is a double below the knee amputee who runs on carbon $\mathrm{J}$ shaped fibre blades. He represents a fusion of humanity and technology that will become an increasingly pressing issue for the sporting arena in the coming years. In this essay I use Pistorius as a case study to investigate how decisions regarding the use of enhancement technologies in sport should be made.

I argue that the key characteristic that should be assessed is whether Pistorius' prosthetic legs mean that he is competing in a different sport to able-bodied athletes when he runs. I contend that the best method for deciding whether or not Pistorius is competing in the same sport as able-bodied athletes is to adopt a balance of excellences view of sport (Devine, 2010). I use this model to show that the excellence of exploiting technical aids is far more important for Pistorius than it is for his able-bodied counterparts. From this I conclude that what Pistorius does when he runs is not comparable to able-bodied runners. Thus he should not be allowed to compete against able-bodied athletes at the Olympic Games. 


\section{Table of Contents}

INTRODUCTION ...............................................................

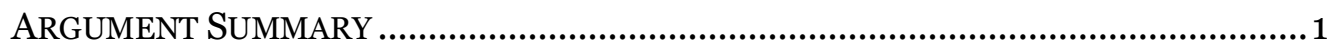

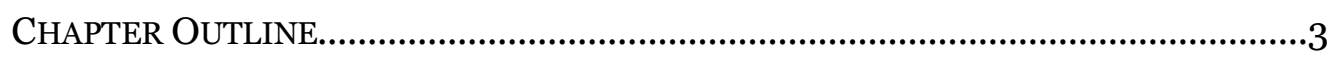

CHAPTER 1: HOW TO ASSESS WHETHER OSCAR PISTORIUS SHOULD

BE ALLOWED TO COMPETE ...................................................6 6

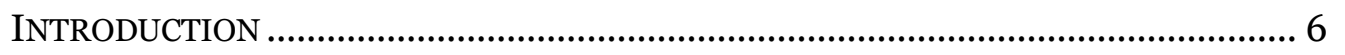

THE PROBLEM WITH AdVANTAGES IN SPORT ................................................... 8

DRAWING A LINE BETWEEN NATURAL AND ARTIFICIAL ..........................................16

THE TREATMENT-ENHANCEMENT DiSTINCTION................................................ 23

THE IMPORTANCE OF IDENTIFYING …............................................................ 29

Is PISTORIUS COMPETING IN THE SAME SPORT? .................................................35

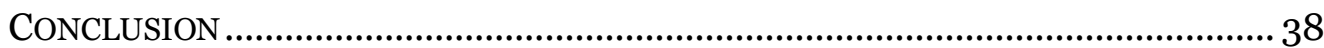

\section{CHAPTER 2: HOW DO WE DECIDE WHETHER PISTORIUS IS}

COMPETING IN THE SAME SPORT? ....................................41

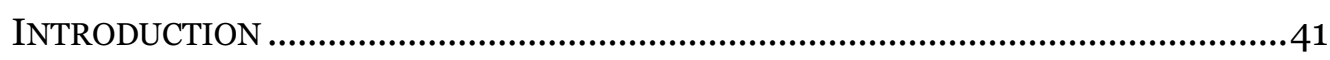

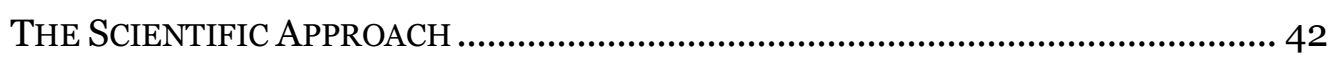

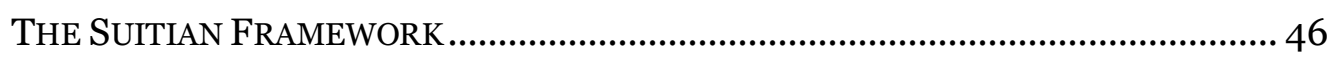

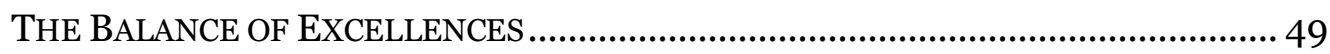

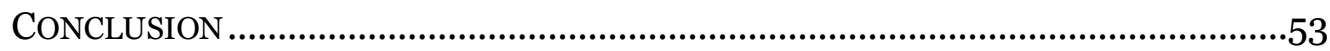

CHAPTER 3: THE BALANCE OF EXCELLENCES ........................55

INTRODUCTION ….....................................................................................5

GOLF AND CASE STUDIES IN THE BALANCE OF EXCELLENCES .............................. 56

THE BALANCE OF EXCELLENCES OF 4OOM RUNNING .........................................61

DOES PISTORIUS UPSET THE BALANCE OF EXCELLENCES ..................................... 63

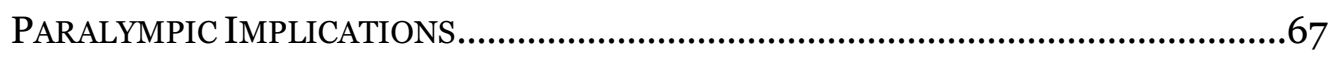

How Do We Solve A Problem Like Pistorius? .............................................. 69

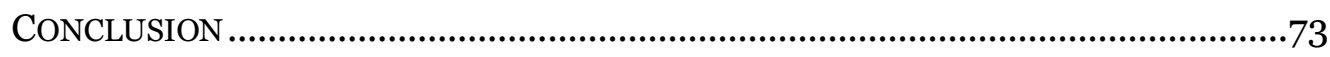

CONCLUSION .............................................................................75

ARGUMENT SUMMARY AND IMPLICATIONS......................................................75

WORKS CITED..........................................................................79 


\section{Introduction}

\section{Argument Summary}

From the $27^{\text {th }}$ of July until the $12^{\text {th }}$ of August 2012 the games of the $30^{\text {th }}$ Olympiad took place in London. The $4^{\text {th }}$ of August was a particularly special day in the history of the Olympics as it was the day that the heats of the men's $400 \mathrm{~m}$ took place.

There is a reason the men's $400 \mathrm{~m}$ heats at the 2012 London Olympics were arguably more special than any that had gone before. South African runner Oscar Pistorius became the first athlete to compete at the Olympic Games while running on prosthetic limbs. Pistorius is a double below the knee amputee (T43 under the Paralympic classification system) who runs on Jshaped carbon fibre blades. He represents a fusion of humanity and technology that will become an increasingly pressing issue for the sporting arena in coming years.

Pistorius is a special case, he is the only amputee runner in history to have come close to an Olympic qualifying time, but he is also a pioneer. Like all pioneers he is leading the way for others to follow. One of the side effects of the most recent Iraq and Afghanistan wars is large number of young people, who would otherwise be in peak physical condition, having their limbs blown off. Fortunately for them they are living in a great time to lose arms and legs. Unlike the poor souls maimed in the First and Second World Wars, modern amputees can be equipped with prostheses that allow them to lead full lives. What does this have to do with elite sport? The British Military and British Paralympic Association have struck a deal whereby wounded soldiers have 
been recruited to boost hopes for future medal hauls (Beard, 2007). While it may seem exploitative, it offers excellent rehabilitation for the wounded soldiers. This increase in young, fit, amputees also increases the chances of there being others capable of following in Pistorius' footsteps and attempting to compete in the Olympic Games. So it is important to establish what to do about athletes who rely on prostheses competing against those who do not.

Another side effect of so many soldiers losing limbs in Iraq and Afghanistan is that the American and British militaries have invested a lot of money in new prosthetic technologies. Many innovations in technology that we take for granted today spawned from military investment during wartime. Prosthetic limbs may be no different. The technology in prosthetic limbs used for running has not changed radically since the 1980 os, but now there is increased demand for highly functional prosthetic limbs. Hugh Herr is head of the Biomechatronics research group at the MIT. He invented the Flex-Foot Cheetah running prostheses used by Pistorius and other top Paralympians. Herr predicts that within thirty years advances in technology will allow amputees to outperform able-bodied runners (Phillip, 2012). If Herr is correct then it is imperative that we decide how to assess what technology should be allowed and what should be prohibited in sporting competitions. We cannot predict exactly what such technology will be. However, by using Pistorius as a case study, we can establish a framework to use when making such decisions if and when they arise.

Since he declared his intentions to compete against able-bodied athletes in 2007, Pistorius has been the centre of controversy. Many points have been raised in the debate over whether he should be able to compete in the Olympic Games. Issues ranging from his presence posing a physical risk to other athletes, to claims his inclusion would corrupt the purity of the world's marquee sporting event.

In this essay I will argue that the key to assessing whether Pistorius should be able to compete is whether he is competing in the same sport as able-bodied 
athletes. I will assert that the best method for determining this is to adapt John William Devine's view of sport (2010). Devine argues that sports are made up of the pursuit of certain excellences. Anytime the balance of these excellences is upset, causing one excellence to become more dominant than another, the balance must be redressed. I will argue that Pistorius tips the balance of excellences of 400m running too far in favour of exploiting technical aids. As a result he is not competing in the same sport as able-bodied athletes when he runs and should not be allowed to compete at the Olympic Games.

\section{Chapter Outline}

This essay is divided into three chapters. The first chapter is dedicated to establishing how to decide whether Pistorius should be allowed to compete at the Olympics. It will begin with a discussion of the controversy surrounding Pistorius' attempts to qualify for the Olympics. It will then discuss five possible ways of determining Pistorius' Olympic eligibility:

- Whether he gains an advantage over able-bodied competitors

- Drawing a line between what is natural and what is artificial

- Distinguishing augmentations that are treatments from those that are enhancements which push the user beyond normal levels of functioning

- Assessing the ability of spectators to identify with enhanced athletes

- Whether Pistorius is competing in the same sport as able-bodeid athletes

I will argue that the first four possible solutions are not adequate for dealing with Pistorius' case. I will start by dismissing the first option on the grounds that advantages are abundant in sport, and to consistently ban advantages would completely destroy the face of sport as we know it. I will argue that the same is true of artificial factors in sport; this section will include a critical analysis of an evolved form of the natural-artificial distinction proposed by Clifton Perry (1983). I will object to Perry's argument on the grounds that it is only suited to assessing technology which is available to all athletes, which is not the case for Pistorius at the Olympics. I will contend that the treatmentenhancement distinction cannot give a definition of what it would mean to 
return Pistorius to a normal level of functioning. Not without such a definition having dire consequences for either the Olympics or the Paralympics. Next I will argue that as long as technological enhancements do not stop their user being human we will always be allowed to relate to athletes. I will also argue that there is something more important to consider than the wellbeing of the spectators: the wellbeing of the sport itself. I will conclude the first chapter by arguing that the best way for determining whether Pistorius should be allowed to compete at the Olympics is to decide whether he is competing in the same sport as able-bodied athletes. This is a strategy that takes into account the interests of the competitors, the spectators, and the sport as an end in itself.

In the second chapter I will investigate how we should decide whether Pistorius is competing in the same sport as able-bodied athletes. I will discuss the following possible methods:

- Using scientific testing to determine whether Pistorius runs in the same way that able-bodied atheletes run

- Using Bernard Suits (1978) framework for defining games to assess what it is to take part in the Olympic 40om

- Assess whether Pistorius maintains the balance of excellences in Olympic 40om running

I will argue that scientific testing alone is not satisfactory, as it does not justify why it is important to run in a certain way at the Olympics. I will deny Suits' definition of games provides adequate justification for why the rules that help define a sport exist. I will end the chapter by discussing John William Devine's (2010) theory, that sport is the pursuit of certain excellences and that anything that tips the balance of excellences in a certain sport must be redressed. I will conclude that this is the ideal way to determine Pistorius' eligibility. This is because it preserves the nature of sport, by ensuring athletes are competing in comparable terms, without preventing progress within a sport.

I will start the final chapter of this essay by demonstrating how the balance of excellences can be applied to situations were technology threatens to alter the 
nature of a sport. I will do this by using two recent case studies from golf. I will then establish what excellences of Olympic 40om running are in their most basic terms:

1. Going fast

2. Using your body to propel yourself around a track

3. Exploiting technical aids

I will demonstrate why the balance of these excellences is important by comparing running with motor racing. This will show that using your body to propel yourself around a track is the dominant excellence in 400m running, with exploiting technical aids playing a nominal role. After I have established the balance of excellences in Olympic 40om running I will discuss whether Pistorius upsets the balance. I will argue that he tips the balance of excellences of 40om running too far in favour of exploiting technical aids. As a result he is not competing in the sport of $400 \mathrm{~m}$ running, instead he is competing in the sport of T43 400m running. Therefore, he should not be allowed to compete against able-bodied athletes at the Olympic Games. I will end the third chapter by arguing that double and single amputee athletes also display significantly different excellences when they run. Due to this difference I will conclude that Pistorius should not compete against single-amputee athletes as is currently the case at the Paralympics. I will contend that if single and double amputee athletes are to continue competing against each other at the Paralympics then they must be measured differently. I will suggest that a method for comparing differently-abled athletes can be borrowed from swimming. This will allow single and double-amputee athletes to continue to have adequate completion until such a time that there are enough athletes in each classification to justify having separate events. 


\section{Chapter 1: \\ How to Assess Whether Oscar Pistorius Should be Allowed to Compete}

\section{Introduction}

Before ruling on whether Oscar Pistorius should be allowed to compete at the Olympics it is important to first decide how such a decision will be made. In this chapter I will critically assess several potential methods for determining whether Pistorius is eligible to compete against his able-bodied counterparts.

I will begin by looking at whether he gains an advantage over other competitors. This was the reasoning behind the International Association of Athletics Federations' (IAAF) decision to ban him in 2008. It was also the focus of much debate in the media during the lead up to the 2012 London Olympic Games. I will begin by discussing the IAAF's reasons for banning Pistorius. I will then argue that the existence of an advantage does not warrant banning an individual. This is because advantages are ubiquitous in sport. Following this I will propose that basing such decisions on unfair advantages is a more reasonable tactic, but still an ineffective one. I will argue that banning athletes from competition due to them having unfair advantages sets an undesirable precedent. This would either lead to banning athletes from certain geographical areas from competition, or the prohibition of various widely accepted training techniques and equipment that would lead to a regression in sport. 
In the second section of this chapter I will investigate the argument that we should distinguish between natural and artificial when deciding what to allow in sport. I will argue that any distinctions between natural and artificial are unhelpful as sport is full of many integral artificial aids. This will be followed by an examination of Clifton Perry's proposed solution: distinguishing between supplementing and exploiting natural ability with technology (1983, p. 308). I will argue that Perry's system is not a satisfactory solution for Pistorius' case because it is suited to assessing technologies that are available to every competitor. Pistorius, however, is the only competitor with access to prosthetic limb technology at the Olympic Games.

I will then investigate the treatment-enhancement distinction as a method for determining Pistorius' eligibility. I will discuss the objection that the treatment-enhancement distinction draws arbitrary lines between similar cases. I will argue that the treatment-enhancement distinction is ineffective in dealing with Pistorius' case. This is because it is impossible to define what normal functioning would be for Pistorius without creating undesirable consequences for the sport he competes in (either by reducing top Paralympic athletes to farcically slow speeds, or by allowing the otherwise unathletic to compete at top sporting events with the aid of technology).

Following this I will examine Nick Agar's view that the most important part of elite sport is its spectators. Therefore, when making decisions about enhancement technologies we should have their best interests at heart (Agar, 2011). I will adapt Agar's argument, that performance enhancing drugs should banned on the basis that they make us unable to relate athletes, to the case of Pistorius. I will argue that there is something more important to sport than the spectators: the sport itself.

Finally, I will argue that the best criterion for assessing whether Pistorius should be allowed to compete is whether he is competing in the same sport as able-bodied athletes. I will conclude that if Pistorius, or the technology that he 
uses, fundamentally alters the sport of 40om running then he should not be allowed to compete against able-bodied athletes at the Olympic Games.

\section{The Problem with Advantages in Sport}

When deciding on what criteria should be used to assess whether Oscar Pistorius should be allowed to compete at the Olympics, the most obvious place to start is to examine whether his carbon fibre prosthetic legs give him an advantage over his fellow competitors. This is the most obvious place to start because it is the reason the IAAF banned Pistorius from able-bodied competitions in 2008. In the lead up to the 2012 Olympic Games it also the dominated the discourse amongst spectators and in the media. In this section I will start by describing the reasoning behind Pistorius' original ban, as well as it being overturned by the Court of Arbitration for Sport (CAS). I will then go into detail about the disagreement between the scientists who represented Pistorius at his CAS hearing regarding whether his prosthetic legs gave him an advantage over able-bodied runners. I will conclude that even if a consensus could be reached about whether Pistorius has an advantage, advantage alone is not enough to warrant banning an athlete, given that advantages are ubiquitous in sport. In the second half of this section I will discuss unfair advantages in sport. In the process I will apply the theory of unfair advantages. I will use S.D. Edwards' arguments against unfair advantage to show that if we were to consistently ban athletes on the basis of them having an unfair advantage we would risk banning everyone from sport. I will finish this section by showing the problems arising from basing decisions on accessibility because it ignores important factors about the sports that athletes are involved in.

In 2008 the IAAF banned Pistorius from attempting to qualify for the Beijing Olmpics for violating rule 144.2. The rule had been updated that year to state that the following technical aids were prohibited: 
... any technical device that incorporates springs, wheels or any other element that provides the user with an advantage over another athlete not using such a device. (International Association of Athletics Federations , 2008, p. 100)

The IAAF ruled that Pistorius' prosthetic legs were springs that provided him with an advantage over the able-bodied athletes who were not using them. Pistorius assembled his own team of lawyers and scientists in order to challenge the IAAF's ruling in the CAS. The scientific team assembled to defend Pistorius at the CAS were tasked with disproving the IAAF's claim that Pistorius' carbon fibre blades consume less energy than the legs of able-bodied runners. This claim was based on evidence that they converted energy more efficiently than a human leg allowing him to run faster for longer due to their spring-like nature (Dugas \& Tucker, 2008). The findings of Pistorius' team comprehensively disproved the IAAF's argument. They concluded that he was "similar to intact-limb runners physiologically but dissimilar mechanically." (Weyand, et al., 2009, p. 910). That is not to say that their findings comprehensively demonstrated his prosthetic legs did not give him an advantage. Rather, their findings showed that the Flex-Foot Cheetahs do not give him an advantage in the area that the IAAF claimed they did.

Indeed, the authors of the paper disagreed upon the nature of the advantage that Pistorius gained from his artificial limbs. The members of the scientific team published competing theories on what made Pistorius so quick and whether his prosthetic legs were the source of an advantage over able-bodied athletes. Two of the scientists that defended Pistorius at the CAS, Peter G. Weyand and Matthew W. Bundle, claim that Flex-Foot Cheetahs give Pistorius a massive advantage. The reason for this comes down to the mechanics of sprinting, which they describe as:

Three mechanical variables constrain the speeds of human runners: 1) how quickly the limbs can be repositioned for successive steps, 2) the forward distance the body travels while the foot is in contact with the ground, and 3) how much force the limbs can apply to the ground in relation to the body's weight (2009, p. 1011). 
When tested, Weyand and Bundle found the force Pistorius can apply to the ground in order to propel himself while running (3) is $65 \%$ lower than that of able-bodied athletes yet he is one of the quickest 400m runners in the world (2009, p. 1011). Therefore, Weyand and Bundle conclude that Pistorius' artificial legs must be giving him an advantage in the other two areas of running.

First, they argue that the relatively light weight of Pistorius' carbon fibre prostheses compared to his able-bodied competitors legs (Flex-Foot Cheetahs weigh approximately half as much as intact lower legs) allows Pistorius to have a quicker stride than his competitors. When Weyand, Bundle and their team tested him in a lab, Pistorius' stride frequencies were $15.8 \%$ greater than the able-bodied athletes he was tested against. Not only were Pistorius' stride frequencies greater than the athletes they tested him against, according to Weyand and Bundle, they are 10\% greater than those of the two fastest athletes in human history (2009, p. 1011). The reason having greater stride frequencies provides an advantage is quite simple: the quicker you move your legs, the quicker you run.

The second thing that Weyand and Bundle claim gives Pistorius an advantage over his able-bodied opponents is his length of stride. Specifically his contact length (the length of his leg at the point where it touches the ground while running) compared to the length of his legs, and his contact length compared to his height. Their research found that Pistorius' contact length-to-leg length ratio was $9.6 \%$ greater than that of the able-bodied athletes they tested him against, and that his contact length-to-height ratio was $16.2 \%$ greater (2009, p. 1011). Why is this an advantage for Pistorius? Once again it is rather simple: the longer an athlete's stride is, the fewer strides they need to take in a race.

If you are moving your legs at the same speed as someone else, but you have a longer stride, you will be faster than them. Not only do Pistorius' prostheses give him a relatively longer stride than his able-bodied opponents, but they allow him to move his legs faster too. The evidence provided by Weyland and 
Bundle seems to point to Pistorius gaining an advantage over his competitors by wearing Flex-Foot Cheetahs. Indeed, they calculate that the $\mathrm{J}$-shaped carbon fibre blades improve his time over $400 \mathrm{~m}$ by almost 12 seconds when compared to what his stride frequency and contact length ratios would be if he had natural legs (2009, p. 1012).

The remaining scientists who defended Pistorius at the CAS: Rodger Kram, Alena M. Grabowski, Craig P. McGowan, Mary Beth Brown, and Hugh M. Herr, refuted the claims of Weyand and Bundle. Kram et al. argue that there could be valid reasons that explain Pistorius' times, other than his prostheses. The first issue they raise with the findings of Weyand and Bundle is their lack of sample size. Pistorius is the only amputee athlete to ever undergo the kind of testing referred to in their arguments. According to Kram et al., simple experiments could be conducted in order to resolve the issue and gather a greater database of amputee runners (2010, pp. 1012-13). Until such tests are done, it is impossible to tell if his impressive test results are typical of amputee athletes (and they do gain a great advantage by running on prosthetic legs) or if Pistorius is special in this regard.

Kram et al. are particularly scathing of Weyand and Bundle's claim that running prostheses increase Pistorius' time by 12 seconds. While Paralympic runners are generally not as quick as their able-bodied counterparts, they are still top athletes who are in peak physical condition. Pistorius is the quickest amputee runner in history over $400 \mathrm{~m}$ by some margin. As Kram et al. point out "nearly any schoolboy athlete can run 400m under 6os" (2010, p. 1014). Yet Weyand and Bundle essentially argue that if Pistorius were able-bodied and did not have the use of Flex-Foot Cheetahs he would not be able to win a high school track and field event

While Kram et al. admit that Pistorius' swing frequencies are quick, they do not see them as the massive outlier that Weyand and Bundle argue they are. Instead they argue the frequencies are within an acceptable range of variation for elite sprinters (2010, p. 1013). Weyand and Bundle make much of the 
lightweight nature of modern running prostheses contributing to the minimal leg swing time of Pistorius. Kram et al. point out that some Paralympic sprinters add extra mass to their prostheses, which would be counterintuitive if being light was the most important thing about a running prosthesis (2010, p. 1013). The scientific quintet also takes issue with Weyand and Blundle's claims about the amount of force that needs to be exerted on the ground in order to run fast. They point out that there has been no data published in this area with regards to unilateral amputees (amputees with one leg still intact). Such data would allow for a direct comparison between the force exerted by an intact limb and a prosthetic limb, as opposed to a comparison between a single bilateral amputee and a handful of able-bodied athletes.

As I have shown above, there is no scientific consensus about whether FlexFoot Cheetahs give Pistorius an advantage over able-bodied athletes. Even if there were it would seem a strange reason to ban an athlete from competing. The wording of rule 144.2 states that it is prohibited to use:

... any technical device that incorporates springs, wheels or any other element that provides the user with an advantage over another athlete not using such a device. (International Association of Athletics Federations , 2008, p. 100)

This is a very broad statement. If an athlete chose not to wear shoes then rule 144.2 would seem to imply that all other athletes should be banned from wearing shoes on the basis that the spikes on them give them an advantage over the athlete no using such a device. One might object that running shoes do not incorporate springs or wheels, but they certainly contain "any other element" as included in the wording of rule 144.2. This is just one of many rather ridiculous examples that could be used to point out the flaw in the wording of rule 144.2. Indeed, on this basis Pistorius should be banned from using Flex-Foot Cheetahs at Paralympic level too, as not all amputee athletes wear them. Perhaps it would be more appropriate to change the wording from "provides the user with an advantage over another athlete" to "provides an unfair advantage". I will now discuss whether banning Pistorius on the grounds of having an unfair advantage might be a more fruitful tactic. 
S.D. Edwards responds to claims that Pistorius has an unfair advantage by offering numerous examples of unfair advantages that are allowed in sport. Such arguments are common in pro-doping literature. The argument usually asserts that unfair advantages abound in sport, so why should we single out this particular instance of an unfair advantage as worthy of prohibition while ignoring all the others (Edwards, 2008, pp. 116-117). The first thing to consider when assessing this argument is how to define an unfair advantage. Fortunately Edwards offers a definition with which we can proceed:

$A$ has an advantage, compared with $B$, since $A$ had access to a resource, $R$, which was unavailable to $B$, and this resource enhanced $A$ 's capacity to achieve a goal shared by both $A$ and $B$. This is 'unfair' since $A$ had access to $R$ and $B$ did not. Principles of equality of opportunity are violated (2008, p. 117).

By such a definition Pistorius clearly has an unfair advantage in the Olympic arena. He has access to a resource (Flex-Foot Cheetahs) that enhances his capacity to achieve the goal of winning Olympic Gold (without them he certainly would not be able to run as fast), a goal that is shared by all those who he is competing against. The able-bodied runners he competes against do not have access to Flex-Foot Cheetahs as they have lower limbs. Thus Pistorius has an unfair advantage.

Edwards points to several examples where unfair advantages are allowed in sport (2008, pp. 115-116). There are some paradigm cases, like that of Eero Mäntyranta. Mäntyranta is a former Finnish cross-country skiing champion who dominated the sport during the 1960s. His dominance was due, in part, to being born with with primary familial and congenital polycythemia (PFCP). PFCP is caused by a mutation in of the erythropoietin receptor gene which lead to Mäntyranta having a 50\% increase in oxygen carrying red blood cells. The name erythropoietin may ring a bell with many sports fans. More commonly known as EPO, it is the performance enhancing drug of choice for endurance athletes because it increases the amount of oxygen carrying red 
blood cells. Mäntyranta had a far greater concentration of red blood cells than is considered normal, giving him amazing endurance. Given that PFCP is a rare condition it would seem that Mäntyranta had an unfair advantage over his competitors. Edwards also offers the example of Miguel Indurain. Indurain had significantly larger lungs than is normal for an adult male: this allowed him to dominate the sport of cycling in the early 90s. From 1991-1995 Indurain won an Olympic and World championship, two Giro d'Italia, and five Tour de France titles. Similarly, athletes who grow up in countries at high altitude will likely develop better natural endurance than athletes who grow up in countries at sea level. Then there are the most ubiquitous unfair advantages: genetic factors. Some people are just better suited genetically to being athletes than others, they do not need to have rare conditions like Mäntyranta, some people are just naturally taller or stronger or faster than others. Yet we allow these people to compete, we do not cry foul at the unfair advantage that they have in the way that people do with regards to Pistorius.

Despite their clear advantages, and access to physical resources that no other athletes had, there is no suggestion that Indurain or Mäntyranta should have been banned from competition in the same way that people argue for Pistorius' exclusion. Perhaps the reason that we do not object to such instances of unfair advantage as displayed by Indurain and Mäntyranta is that they are part of the athletes' physiology, whereas in Pistorius' case we are talking about a piece of technology. There are also numerous examples of unfair advantages provided by technology being allowed in sport. As Edwards points out the US track and field team have access to coaching, training equipment, and nutritional resources that most athletes in poorer countries can only dream of (2008, p. 116). If there were any consistency there would also be calls to ban athletes from countries from with substantial investment in their sporting infrastructure. It would however cause real stagnation in the sporting arena if new training methods were banned until they were available to everyone, not to mention the cost and impracticality of policing such a policy. 
Accessibility is also an important concept in the unfair advantages argument. The argument for accessibility states that an advantage is unfair if it is not accessible to every competitor. Clifton Perry posits that the argument for accessibility is unhelpful due to the fact that there are advantages that we would wish to outlaw even if they were accessible to all competitors. Perry uses the example of a marathon runner taking a car for the portion of the race in order to win while the other competitors remained on foot. He continues his marathon example by stating that even if all the competitors in the race were to use a car for a portion of it, we would not wish to allow marathon competitors to use cars. He states that the reason we would not wish to allow marathon runners to use cars is that it would go against what is required to run a marathon (1983, pp. 308-9). So there are clearly examples whereby we would not wish to allow certain pieces of technology to be used even if they were fairly and evenly distributed amongst competitors.

In this section I have discussed the IAAF's decision to ban Oscar Pistorius from competing against able-bodied athletes. Their decision was based on the carbon fibre Flex-Foot Cheetah prosthetic legs that Pistorius runs on giving him an advantage over athletes not using them. I have shown that the broad wording of the IAAF's rule 144.2 implies that almost every technical aid should be banned from sport. I then discussed a potentially more reasonable approach of banning those who have an unfair advantage, but reached the same conclusion. Adopting a stance whereby any piece of equipment that provides advantage over other athletes, or any instance of an unfair advantage, is banned would lead to sport being stripped of its diversity. Furthermore given the different benefits that come with geographical location and genetic heritage it is an impossible task to remove all unfair advantages from sport. Using Clifton Perry's argument I have also shown the problems with using accessibility as the basis for deciding what technology should be allowed in sport, as it does not take into account certain important factors about the sport the athletes are involved in. 


\section{Drawing a Line Between Natural and Artificial}

It is important to note that showing sports administrators to be inconsistent in the way they decide what technology should or should not be banned does not prove anything as far as allowing Pistorius to compete goes. Rather than saying "look, these things are allowed, so Pistorius should be allowed," one could look at it from the opposite angle. Perhaps this inconsistency shows there are many technologies that are allowed in sport that should not be allowed. Maybe we have gone away from what sport is really about: displays of human athletic excellence. Perhaps Pistorius is just the high profile case that was required for us to see the light. So should we eschew all this technology, maybe we could return to make athletes compete naked like they did at the first Olympic Games in ancient Greece? In this section I will discuss the possibility of using the difference between what is natural and what is artificial to decide what should and not be allowed in sport. I will argue that distinctions based purely on a divide between natural and artificial do not work in sports given their artificial nature. I will then discuss Clifton Perry's alternative view that we should differentiate between technologies that exploit the natural abilities of athletes and technologies that supplement the natural abilities of athletes. I will conclude that Perry's proposed solution is not an adequate way of dealing with Pistorius' case as it is suited to assessing technologies that are available to all competitors, not cases where only one competitor has access to the technology in question.

When discussing the difference between fair and unfair advantages in sports Clifton Perry points out that there are those who have put forward arguments about the distinction between natural and artificial (1983, p. 308). In the performance enhancing drugs debate such distinctions have sometimes been used to justify why it is prohibited to inject a substance, like endurance enhancer EPO, even though it occurs naturally in the body. Perry argues that such distinctions are not helpful due to the fact that there are many things that contribute to an athlete's performance, such as their shoes, which are unquestionably artificial (1983, p. 308). I do not see this inconsistency argument alone as a reason to dismiss the natural-artificial distinction out of 
hand. As mentioned above, even if Perry is correct, rather than just assuming that artificial aids must be allowed in sport because there are already examples of artificial aids in use, it is worth investigating the possibility that the artificial performance aids already in use should also be banned.

If sporting performance is the measure of one person's ability against another, then why not make athletes compete naked as they did at the ancient Olympic Games? Or, if that seems too drastic, revert to the days of amateurism where gentleman athletes would not train. One possible reason that such scenarios are not desirable is that sports, by their very nature, are artificially constructed. The act of running a certain distance or getting a ball into a hoop are not naturally occurring concepts: they are the constructs of human beings who wish to test and entertain themselves. Furthermore many sports would not exist without artificial equipment. Take football for example. The ball and posts required to play the game are artificial constructions. Not just because they are, for the most part, constructed out of manmade materials. Even back in the early days of the sport, when footballs were made from leather, and goalposts constructed from wood, they were still constructed by men for the specific purpose of playing a game. For sports to exist, it is necessary that they incorporate artificial elements.

Perry argues that if we are going to use natural and artificial as a guide, a better distinction to make would be between an athlete enhancing their performance by supplementing their natural abilities and an athlete enhancing their performance by exploiting their natural abilities (1983, p. 309). The difference between the two is that an athlete exploiting her natural abilities is merely utilising what she already has. For example, a boxer who trains hard to build his muscles and increase his speed to give himself a more powerful punch is exploiting his body's natural ability to create power that will hurt his opponent. Whereas a boxer inserting metal plates in his gloves is supplementing his natural abilities by adding an outside component that will assist his abilities through no extra work (Perry, 1983, p. 309). 
Before discussing Pistorius it is important to acknowledge that Perry himself questions the effectiveness of the exploitation-supplementation distinction. This is due to its inability to differentiate between seemingly clear-cut cases of technologies that we would and would not want to allow in sport. Perry uses the example of the poles used in pole vaulting (1983, p. 309). There are no rules governing the length of the poles, or the material that the poles used are made from. They were originally made from solid wood, then bamboo. Current poles are made out of a combination of carbon fibre and fibreglass. As new materials made poles lighter and more flexible, the heights being cleared have increased. There have undoubtedly been non-pole related improvements in sports science that have attributed to these increased heights being vaulted. Yet I suspect that current Olympic champion Jenn Suhr would not have won gold had she been using a wooden pole while her competitors used the latest technology available. The newer poles are supplementing the athletes' ability. Perry states: "athletes are not better vaulters when particular poles are used but vaulting limits are consistently higher with the use of these poles" (1983, p. 309). Yet there is no resistance to new pole technology, the transition from wood to fibreglass has not harmed the sport in any way. It has helped it move forward and evolve without radically changing it. The same could be said about the bicycles used in the Tour de France. The switch from steel to carbon fibre framed bicycles has supplemented the performances of riders, but they have not been detrimental to the sport, and very few people would wish to see them outlawed.

There are also problems encountered with cases of exploiting the natural ability of an athlete with, what would seem to most people, paradigm cases of technology that should not be allowed. Take steroids, most people believe that athletes should be banned if they are found guilty of using them. However, according to the exploitation-supplementation model, steroids should be allowed. Steroids do not supplement an athlete's performance, they allow them to recover more quickly from vigorous workouts and thus train harder, more often. Steroids allow athletes to better exploit their natural ability (Perry, 1983, pp. 309-10). 
Pistorius himself presents a very difficult case for the exploitationsupplementation model. This is because, according Perry's reasoning, whether it is fair for him to compete against able-bodied athletes using running prostheses hinges on how his relationship to technology is defined. The question is whether the Flex-Foot Cheetahs he uses are exploiting his natural athletic ability by allowing him to run in a similar way to able-bodied athletes, or whether he is supplementing his natural abilities with high-tech purpose built carbon fibre prostheses that allow him to run faster than he would otherwise be able to.

Such difficult cases as the ones outlined above lead Perry to offer the following three amendments to the exploitation-supplementation model of advantage:

1. The augmented performance must come about as a result of the endeavour to eliminate the deleterious effects which are associated with the practice of the sport.

2. The enhanced performance may be seen as the reaction to an undesired inhibitor to better performances.

3. The enhanced performances may simply be the result of an agreed upon elimination or addition of an empirical factor (1983, p. 310).

I will now frame the above amendments in terms of Pistorius competing against able-bodied athletes. I will start by showing how they apply to sport in general by continuing with the example of the evolution of poles used in pole vaulting. I will then apply them to Pistorius and his running prostheses.

The first amendment suggested is that the enhanced performance given to an athlete must have come about due to an attempt to eliminate harmful consequences of the sport (Perry, 1983, p. 310). At first glance, when applied to the case of modern poles in pole vaulting, this caveat might not seem to go very far towards justifying their existence. Modern poles are, however, far stronger and more reliable than their bamboo predecessors. This means that 
modern poles are less likely to break during use, leading to a decreased risk in injury for those using them.

When applied to Pistorius, this first amendment raises the question of the primary function of the Flex-Foot Cheetahs that he runs on. There have been questions raised over whether Flex-Foot Cheetahs are true prostheses as they are not useful in everyday life due to their specific design and function (Chockalingam, Thomas, Smith, \& Dunning, 2011, pp. 482-483). They are clearly very useful in Pistorius' everyday life as a professional athlete. The fact that they are designed specifically for running means that they supplement Pistorius' performance in a way that regular prosthetic legs do not. Nevertheless, their sport-specific design also make running far more comfortable for the athletes who use them. So it might seem that Perry's first amendment favours allowing Pistorius to use prosthetic limbs in competition. However, Perry's amendment states that: "the augmented performance must come about as a result of the endeavour to eliminate the deleterious effects which are associated with the practice of the sport" (Perry, 1983, p. 310). Pistorius uses his prosthetic legs to overcome his lack of lower limbs therefore an objection could be made that lacking lower limbs is not an undesirable byproduct of competing in $400 \mathrm{~m}$ running.

Pistorius' running prostheses are certainly necessary for him to avoid the injuries that would occur to him if he were to attempt to run without prostheses, or even if he were to run wearing far more rudimentary prostheses. To reiterate, Perry's first amendment states that for something that alters an athletes' performance may be allowed if it is the "result of the endeavour to eliminate the deleterious effects which are associated with the practice of the sport" (1983, p. 310). The deleterious effects that come about through running without lower legs are not associated with the practice of 40om running in the Olympic Games. Equipment like running shoes combat injury to the feet of Olympic runners while increasing their times by providing better grip on the track. Pistorius' prostheses do not address the same problems, as he does not have feet. Indeed, Pistorius' prostheses do not address deleterious effects experienced by any Olympic 40om runner 
throughout history. Certainly they are necessary for combating the harmful effects experienced by competitors in T43 and T44 400m running, ${ }^{1}$ but $400 \mathrm{~m}$ running at the Paralympics is not the same as 400m running at the Olympics. When it comes to the sport of Olympic 40om running, Perry's first amendment does not justify the use of prosthetic limbs.

The second amendment proposed by Perry is for something that enhances an athlete's performance to be allowed if it is a reaction to an undesired inhibitor (1983, p. 310). This is where modern pole vaulting can find comfort. While modern poles clearly supplement performance, they do so by removing an undesired inhibitor. In this case the undesired inhibitor was the lack of strength and flexion in poles made from other materials, as well as their greater weight. The new poles did not alter what the vaulters were trying to achieve or the way that they were trying to achieve it, they just helped them get around the restrictions of old poles.

This amendment also favours Pistorius at first glance. Pistorius has a clear inhibitor: not having legs. His running prostheses allow him to remove this inhibitor by giving him the ability to run. Yet, as above, Perry's argument seems designed to sanction methods of enhancement that are available to all. Pistorius' Flex-Foot Cheetahs are not available to all Olympic athletes. Likewise, the performance inhibitor that is being encountered is not a performance inhibitor for athletes competing in the Olympic 40om race. It is a performance inhibitor to athletes competing in the Paralympic T43 and T44 40om race. The second amendment certainly favours any technology at Paralympic level that can improve the running ability of amputee athletes, but it does not back the likes of Pistorius being able to use them in Olympic competition.

Perry's final proposed amendment is that enhanced performances may just be the result of agreeing to eliminate or add an empirical factor. It may seem

\footnotetext{
${ }^{1}$ Pistorius is classified as a T43 athlete as he is a double below the knee amputee. However, due to lack of competition he competes in the T44 class at the Paralympics against predominantly single amputee athletes.
} 
strange to follow such well-reasoned philosophical arguments with a statement to the effect of: " $x$ should be banned... Unless we say that it is allowed.” But, as I pointed out above, sport by its very nature is arbitrary and artificially defined. So this amendment is not necessarily a bad idea, but any inclusions should be justified, or at least not objectionable. There is, for example, currently nothing objectionable about allowing pole vaulters to use made out of any material or having them any length. Nothing about the sport of pole vaulting is corrupted by such allowances. If, however, a pole were introduced made of a material so advanced that the athlete using it had to do no work whatsoever in order to clear 10m, this would be objectionable. Such a pole would seem to remove an important aspect of the sport,

The IAAF has made the decision to allow Pistorius to compete at the Olympics. Empirically Pistorius passed the third amendment, although they could just as easily change their mind and ban him again and be in line with the third amendment. Allowing an athlete with prosthetic legs to compete against able-bodied athletes in a running event changes seems like it may have the potential to change the nature of the sport. On the flipside, there seems to be no problem with Pistorius and other athletes using Flex-Foot Cheetahs, or other running prostheses, in the Paralympics. Their use has been agreed upon, not only does it not change the nature of the sport, but most importantly it is intrinsic to the sports of T43 and T44 400m running.

I began this section by discussing whether distinguishing between what is natural and what is artificial would be a good way of deciding what should and should not be allowed in sport. I argued that it was not a good method because sports themselves are artificial constructs. I then discussed Clifton Perry's slightly evolved take on the natural-artificial distinction. Perry's view of performance enhancing technologies rests on the distinction between an athlete enhancing their performance though supplementation and exploiting their natural abilities. Which of the two applies to Pistorius? It depends on what event you are discussing. When Pistorius is competing at the Paralympics the prostheses he uses exploit his natural ability as an amputee runner. However, when he competes against able-bodied athletes his 
performance must be viewed within a framework of athletes who do not use prosthetic legs. Therefore Pistorius is enhancing his performance by supplementing his ability as a 'natural' athlete with running prostheses.

Of the three amendments Perry offers to the above rule, none of them present compelling arguments in favour of allowing Pistorius to compete in the Olympics. Taken at face value the first and second amendment offer support to Pistorius, but when examined more closely this is not the case. Each of the amendments put forward by Perry fails to support Pistorius' cause because his predicaments are unique to him in the context of the Olympic arena. Perry's amendments are designed to be applied to technology that is available to all competitors. They might support arguments in favour of allowing new prosthetic technology to be introduced in the Paralympics because such technology will be available to all athletes within the $\mathrm{T}_{43}$ and $\mathrm{T} 44$ categories. Able-bodied athletes do not have the same luxury when it comes to running prostheses. There is an important distinction between what can be allowed in the Paralympics and Olympics. Perry's arguments for allowing performanceenhancing technologies are dependent on that technology being available to all competitors. In the Paralympics the technology Pistorius used is available to all of those who he competes against, ${ }^{2}$ the same cannot be said about the Olympics. This is why Perry's argument is not adequate to assess Pistorius' eligibility in a competition where he is the only athlete with the option of using prosthetic limb technology.

\section{The Treatment-Enhancement Distinction}

A popular method in human enhancement literature for determining what technologies should be allowed is to distinguish between treatment and enhancement. In this section I will start by outlining the treatmentenhancement distinction, and briefly discuss the problems with its seemingly arbitrary distinctions. I will then use the case of Pistorius' prosthetic running legs to show the most problematic aspect of the treatment-enhancement

\footnotetext{
${ }^{2}$ Though the level of availability is different for single and double amputees. This is a problem that I will address in the final chapter.
} 
distinction when applied to sport; athletes are not normal. I will argue that the treatment-enhancement distinction is ineffective in dealing with Pistorius' case as his carbon fibre blades blur the line between treatment and enhancement. I will examine possible methods for defining what a normal level of functioning would be for Pistorius and reject them on the grounds that adopting them would allow unappealing abuses of technology that would go against the nature of athletics. I will conclude that the treatmentenhancement distinction is not a good method for determining Pistorius' Olympic eligibility as it fails to take into account important aspects of the sport that he wishes to compete in.

The treatment-enhancement distinction 3 is the argument that when assessing whether we should allow a person to use a piece of technology we should base our decision on whether the technology in question will bring the person using it up to a normal level of functioning or whether it will exceed normal levels of functioning. Proponents of the treatment-enhancement distinction argue that we should only allow people to use technology to alleviate medical conditions in order to improve them to a level that is considered to be normal human functioning. Such instances would be considered treatment. Enhancement on the other hand would be occasions where technology is used to boost otherwise healthy individuals above their normal levels of human functioning (Daniels, 2000, p. 309).

One of the main objections levelled at the treatment enhancement distinction is that it makes seemingly arbitrary distinctions between similar cases. For example:

Johnny is a short 11-year-old boy with documented [Growth Hormone (GH)] deficiency resulting from a brain tumor. His parents are of average height. His predicted adult height without GH treatment is approximately $160 \mathrm{~cm}$ ( 5 feet 3 inches). Billy is a short 11-year-old boy with normal GH secretion according to current testing methods. However, his parents are extremely short, and he has a predicted adult height of $160 \mathrm{~cm}$ ( 5 feet 3 inches). (Daniels, 2000, p. 311)

3 Sometimes called the therapy-enhancement distinction. 
Norman Daniels points out that the fact that Johnny and Billy will suffer the same disadvantages if not treated, and that people will treat them entirely the same makes a distinction whereby one should be treated and the other should not seem entirely arbitrary. (2000, p. 311) In both cases they will be short due to the misfortune of being born with certain genes, yet according to the treatment-enhancement distinction one should be treated and the other should not.

Furthermore, the lines that are drawn between what is normal and what is considered sub-normal are often arbitrary. It is difficult to give justification as to why $x$ should be considered the cut off point for those who should be allowed treatment, as opposed to $x+1$. Drawing lines to demarcate what is considered normal becomes even more problematic when the treatment enhancement distinction is applied to the sporting arena. This is because what can be seen as a disability in some facets of life may be seen as an advantage in the sporting arena. Sumo wrestlers, for example are so morbidly obese that they require young apprentice sumos to take care of their personal hygiene after going to the toilet (van Hilvoorde \& Landeweerd, 2008, p. 99). Basketball is another prime example of normality being skewed in sport. The average height of an American male is 5 feet 10 inches $(178.2 \mathrm{~cm})$, yet the average height of a player in the NBA is 6 feet 7 inches $(204 \mathrm{~cm})$. Oscar Pistorius offers a particularly difficult case for proponents of the treatmentenhancement distinction.

The reason that Pistorius' case is so difficult is that the Flex-Foot Cheetah legs he runs on seem to blur the line between treatment and enhancement. Without knowing how fast Pistorius would have been able to run if he had been born with fibulas it is impossible to know what it would be to return him to a normal level of ability. Even if tests could be devised to show what the ultimate speed a man with Pistorius' physical attributes could reach, it would not be helpful. There are too many unknowable variables. Perhaps if Pistorius were born with intact legs he would never have gotten into athletics, maybe he would have taken his health for granted and lead a sedentary lifestyle. Anticipating how fast he would have been seems no more fruitful than 
anticipating how fast I might have been if I had been born with pushy parents who trained me from a young age to be an athletics star. Proponents of the treatment-enhancement distinction may object that we do not need to know how fast Pistorius would have (or could have) been able to run. Instead, all we need to do is know what is it to restore him to a normal level of functioning. Which raises the question: how do we define what a normal level of functioning is?

Perhaps the most obvious way of deciding on a normal level of functioning is to look at what Pistorius requires the prosthetic legs for in the most broad terms: to walk and run. He does not have the ability to walk or run without prosthetic legs and walking and running are considered functionally normal things for human beings to do. Such a broad definition is problematic though, as Gregor Wolbring points out: 'would not any bionic leg be therapeutic for the person without legs even if the properties outdo the “normal” legs?' (2008, p. 154). If we are just concerned with returning the ability to walk and run then there is no cause for concern if an athlete were to use advanced robotic prosthetic legs that allowed him to run at spends of $50 \mathrm{kmph}$. Such a performance would be clearly outside the norms of human functioning. Just because we cannot pinpoint the exact speeds that an individual might be able to run does not mean that we cannot work out a range for what is considered normal. If the boys mentioned above receiving $\mathrm{HGH}$ treatments were to grow to be ten feet tall we would have no difficulty recognizing that they were beyond normal. What if they were to grow to be seven feet tall? Such a case would be pushing the boundaries of normality. Pistorius is certainly not the equivalent of the ten foot man, but he is similar to the seven foot man in that he is in the very top percentile of human functioning.

If a normal level of functioning were to be based on the average athletic ability of the adult male population then Pistorius' carbon fibre blades are certainly enhancements. With a personal best of 45.07 seconds he is probably in the top thousand fastest people over $400 \mathrm{~m}$ ever to have lived. If the average male could run that fast then the Oympics would be a lot more crowded. Given his impressive physical attributes it seems that Pistorius would likely have been 
able to outperform the average person had he been born with intact legs. If Pistorius, and other amputee athletes, were to be forced to only use prosthetic legs that gave them species typical running times it would not only seem quite unfair but would also have farcical consequences for the quality of the Paralympics.

As I mentioned above, elite athletes tend to exist outside of normal functioning. Perhaps then it would be better to judge Pistorius in terms of normal levels of functioning for elite 40om runners. On such criteria Pistorius' prostheses would seem to be a treatment rather than an enhancement. Of the forty-seven runners who finished the first round of the 40om heats at the London Olympics, Pistorius was sixteenth fastest. Not amazing. Not terrible. Average. However, using such criteria would also be problematic. If Pistorius is to be judged on what is normal for an elite athlete then why not let everyone else reach the same criteria. If I were to lose my legs would I be within my rights to get hold of some sort of supercharged robotic legs that would allow me to reach the speeds of elite runners? Don't get me wrong; I do not want to win any medals with these legs, after all, that would be enhancement. I just want legs to make me a middle of the pack Olympic runner: a normal elite athlete. As above there seems to be something very wrong about such a scenario, it would not seem to be in keeping with the spirit of athletics to allow me to take such short cuts.

Given how difficult it is to use athletic ability as a measure for what is considered normal, perhaps it would be prudent to use a more simple method for determining an acceptable level of treatment when it comes to prosthetic limbs. The International Paralympic Committee (IPC) offers a possible solution: height. When competing at the Paralympics the length of the prosthetic legs athletes use is regulated by the IPC based on how tall they would have been if they still had intact legs (International Paralympic Committee, 2011, pp. 44-46). ${ }^{4}$ If height were to be the basis of Pistorius'

\footnotetext{
4 This system is not without its controversy, Pistorius accused Brazilian runner, Alan Fonteles Cardoso Oliveira, of having unnaturally long prosthetic legs when he handed Pistorius his first ever defeat over 200m in London.
} 
assessment using the treatment-enhancement distinction then there would be no problem as his height is within a normal range for someone with his sized torso. It would, however, seem strange if height were to be the defining issue. If someone loses their legs in a car crash we do not say that their disability is that they are now unnaturally short. To do so would be as strange as offering to cure someone with a growth hormone deficiency by giving him or her platform shoes. Pistorius' disability is a lack of functioning legs, not a lack of height. This is not the only problem with using height as the key measure of functionality. If we were to say that as long as someone uses prosthetic legs that keep them within a normal height range then they could compete, the same possibilities for using supercharged robotic legs arise. Once again this seems to go against some very important aspect of the sport of athletics.

In this section I have looked at the treatment-enhancement distinction as a possible method for determining Pistorius' eligibility for the Olympics. I began by outlining the treatment-enhancement distinction and showing that it is a method for regulating the return of those with disabilities to species-typical levels of functioning. I then argued that the treatment-enhancement distinction faces particular difficulty when it is applied to sport-specific cases because top athletes tend to exceed species typical functioning. Using Pistorius as a case study I have shown that there are real problems with defining normal functioning. On the one hand if athletes using prosthetic technology were only allowed to run as fast as the average person there would be farcical implications for the state of the Paralympics with elite athletes restricted to running absurdly slow times. On the other hand if Pistorius were to be measured in terms of normal functioning for top athletes there are implications at the other end of the spectrum. Such a scenario could lead to cases of overweight middle-aged men being fitted with highly advanced prostheses that allow them to run Olympic quality times. The treatmentenhancement distinction fails to take into account important aspects of the sports that it is applied to and as a result it becomes more of a hindrance than a help. 


\section{The Importance of Identifying}

In the previous section I criticized the treatment-enhancement distinction for not taking into account the nature of the sports that the athletes were competing in. In this section I will investigate Nick Agar's view that the most important aspect of elite sports are the spectators' interests. So when we are considering which enhancement technologies to allow in sport we should take into account the spectators' best interests. I will start by looking at Agar's argument that when assessing enhancement technologies we should consider whether the technology affects the spectators' ability to simulate the performances of the athletes they are watching (2011, pp. 152-153). I will argue that Agar's view has merit in its explanation of how we can relate to some athletes more than others. Following this I will assess Pistorius' case using simulation theory. I will explain Pistorius' popularity by introducing the Sports Incongruity Theory to show that the public finds him so interesting because he is a rarity. I will conclude that Agar's arguments do not justify banning enhancement technologies, as we are still able to relate to the performances of those who are very different to us even if it might be difficult to simulate what they are doing.

Nick Agar takes a view of sport whereby elite sports have a duty to the spectator. He argues that without their audiences the phenomenon of elite sport in its current incarnation would not exist. His reasoning is that professional sports require money. A large amount of this money comes from three sources: ticket sales, television rights, and sponsorship. The most obvious correlation between spectator interest and money earned by a sport comes from ticket sales. When people come to watch a sport they pay money for their tickets, which directly benefit the sport. However, the big money earners for most sports are sponsorship and television rights. While there can be some benevolence in terms of sponsorship (perhaps the owner of a company is a childhood fan of a sport and wants to give back to the game they love) most companies who pump money into a sport do so with the hopes of boosting brand recognition. In recent years even the term 'sponsor' as been 
used less and less in many sports, being replaced with terms like 'corporate partner' indicating that the companies involved expect something out of the relationship. What do they want out of the relationship? They want people to buy their products, and in order for people to buy their things they need people to watch the sports that they are sponsoring. Either directly or indirectly those who watch sports are responsible for the amount of money involved.

Thus Agar believes that the spectators' interests should be at the heart of any decisions about the direction that elite sport takes (2011, pp. 149-50). When this train of thought is applied to the issue of enhancement Agar argues that the key issue that must be taken into account is the spectators' ability to relate to an athlete, and simulate their performance (2011, pp. 152-3). The simulation to which he refers is explained by simulation theory: the notion that we recreate the mental processes of others in our own minds to help us explain the reasons for their actions. According to Agar, this explains why we are so interested in seeing an athlete performing at their peak: we imagine what it is like to be them and do what they do.

To illustrate his point Agar draws on one of the greatest goals ever scored in football: Diego Maradona's second goal against England in the 1986 World Cup quarterfinal, described below:

Fed by Hector Enrique, Maradona turned through 180 degrees out on the right, on the halfway line, before slipping between Peter Reid and Peter Beardsley. Next he sped inside centre-back Terry Butcher and fended off a challenge from Terry Fenwick, who had been distracted by the lurking presence of the advancing Jorge Valdano. Maradona slalomed on deep into the penalty box, waited for Peter Shilton to step from his line then dummied left before stepping right to slip the ball past the keeper and over the line just as the recovering Butcher launched another, vain tackle (The Telegraph, 2007). 
According to simulation theory the thrill we get from watching the goal comes from our ability to simulate what it must have been like to jink past each man, and slot the ball into the back of the net. There seems to be some intuitive truth to simulation theory; sports fans often have experience participating in the sport that they follow, and as a result the can relate to the difficulty involved in attempting an outstanding piece of skill. Such first hand experience would presumably lend itself to simulating the performances of top athletes (Davidson, 2011, p. 31). Agar argues that athletes who use artificial enhancements make it more difficult for us to simulate their performances. This is because athletes need to be sufficiently similar to us in order for us to relate to them. The use of artificial enhancement creates a barrier that we are unfamiliar with (Agar, 2011, p. 154).

The first objection that comes to mind in the face of Agar's argument is that athletes are already very different to us, but this has not prevented our enjoyment from watching elite sports. As I mentioned in the previous section, top athletes tend to operate beyond normal levels of human functioning. Elite athletes lead lives that few people can relate to. They must have discipline and control to spend their waking hours training, knowing that any slacking off might cost them the small percentages that can decide the difference between victory and defeat. Elite athletes in big business sports also have riches beyond what most people will ever have; yet these differences do not seem to prevent us enjoying what they do. Perhaps physical difference is the key issue. I am very different to a seven foot tall basketball player in many ways, yet as I write this I am captivated by the NBA playoffs. If Agar's simulation model is accurate then it would seem that I should not be at all interested in whether the San Antonio Spurs are beating the Utah Jazz (53-28 at halftime for the record) as those participating are so different to me. Yet I am, and furthermore I can simulate what it is like to slam dunk despite barely being able to reach the net attached to a standard basketball hoop.

Agar might reply that while professional basketball players are indeed different to me, they are not different in significant ways. They are still just natural men. Men who are taller, and stronger, and have spent a lot more 
money on tattoos, but natural men all the same. Pistorius however is different in a much more significant sense. I can relate to dribbling a basketball around a court, and how difficult it is to make certain shots. I cannot as easily relate to running without legs from the knee down. Very few people in the world can. Pistorius is significantly different from us, which affects our ability to simulate his performance. This would explain why the Paralympics are far less popular to spectators than the Olympics. Most people simply cannot relate. While it might be extremely entertaining to someone born without limbs, most of us simply cannot identify with what Paralympic athletes are doing when they perform. Certainly we may be able to recognise that what they are doing is impressive and worthy of merit. However, it is in the same way that my sister, who cares little about sport, can recognise an outrageous goal in football as something that is impressive. She cannot simulate the processes that go into producing the goal without having experienced what it is like to kick a football. By the same token most people cannot, and will never be able to fully appreciate the processes that go into running without legs unless they have attempted to undertake the task themselves.

Do we then owe it to the spectators to ban disabled athletes from competing against able-bodied athletes, as they will not be able to relate and will lose interest? This is what Agar's theory seems to indicate. Yet the media frenzy surrounding Pistorius indicates that the public are extremely interested in him. At the time of writing (three months before the 2012 Olympic Games start) he is one of the most talked about athletes in the world. The acid test for global popularity, a Google search, reveals 45,500,000 hits for 'Oscar Pistorius'. By contrast the fastest man in history over 100 and 200m, and reigning Olympic champion in arguably the most prestigious event in world sport, 'Usain Bolt' notches up a paltry 15,700,00o hits. Why then is Pistorius so popular if he is a man that we cannot relate to and cannot simulate? One possible answer is sympathy. We feel pity for him. He has overcome adversity, and we all know what it is like to overcome adversity. Perhaps that is what we are simulating and what causes our great interest. Although this does not seem to be the case. Watching him compete genuinely thrills people; he's not just someone we empathise with out of pity. Pistorius himself is often at pains 
to downplay any adversity he has overcome and, in his public persona at least, he is anything but pitiable. So what is going on?

I believe there is a simple explanation for why there is so much fanfare around Pistorius which does not clash with Agar's simulation argument. It is what I shall call the Sports Incongruity Theory. Incongruity (being out of place or different) has been used in the past to explain common elements in what we find humorous (Deckers \& Buttram, 1990). Being incongruous is also a common element that ties together what we find most entertaining about sport. Obviously sport is a form of general entertainment, and it cannot be incongruous all the time or it would no longer be incongruous. What I am talking about is the things about sport that we find extremely entertaining, things that make the highlights reel.

When 'Iron' Mike Tyson bit a chunk out of Evander 'The Real Deal' Holyfield's ear during a boxing match in 1997 the sporting world went into a frenzy. While there was widespread condemnation of the act, it was unquestionably entertaining. However, if every boxing match ended in disqualification due to an ear biting the condemnation of the sport would be intensified and the entertainment value would be gone. This is due to the incongruity of Tyson's actions. It had never been seen before; it was a freakish, unpredictable, bizarre thing to happen. In essence it was what makes sport entertaining at the most extreme end of the scale. It is not always negative or controversial things that fall into this category. Tune into ESPN SportsCentre's Top 10 plays on any given day and you will see a variety of skill from a variety sports which will have one thing in common: incongruity. They are all pieces of skill which are out of the ordinary, for example a hole-in-one in golf, and that is what makes them so entertaining.

Just as the Sports Incongruity Theory can explain why we found Tyson biting Holyfield so entertaining, it can explain why Pistorius has become such a phenomenon. He is different in the world of athletics. Or at least he is different in the world of able-bodied athletics. Just as ear biting in boxing 
would lose its entertainment value if it happened in every fight, amputee athletes would lose their entertainment value if they became the dominant participants in athletics. This theory seems to be backed up by the fact that the Paralympics, where races are contested solely by amputee athletes, receives relatively little fanfare.

So the fact that Pistorius is extremely popular among fans and the media does not contradict Agar's theory due to the reasons why he entertains us. The one off nature of Pistorius provides an incongruous appeal that outweighs the fact that we cannot relate to what he does, or simulate what he is doing when he competes in able-bodied 400m races. This incongruous appeal of Pistorius does not extend to him competing against other amputee athletes, as in that situation he is not an exception. Certainly his dominant performances against other amputee runners are impressive, but the inability of the able-bodied majority to relate makes them less appealing for most spectators than ablebodied competition. This can explain why more people tune into the Olympics than the Paralympics. It might be contested that fewer people watch the Paralympics because performances are not as impressive as they are in the Olympics. However, there are many examples available of people watching a lesser product because they can better relate to it. As I mentioned above people tend to enjoy watching sports that they play or have had involvement with which makes sense as they can better relate to what they are seeing. If watching those who were the best in their field was really all that mattered then it would make sense for me to shun watching a local football match in favour of watching the bobsleigh World Championships, but I do not.

It may be true that spectators cannot simulate Pistorius' performances, but I do not believe that simulation plays a significantly important role in their ability to relate. We can still imagine what it might be like to run on prosthetic legs. Pistorius may be different but he is still human. David Wasserman succinctly sums up why technological enhancement is unlikely to break our ability to relate to athletes: 
During the Beijing Olympics, television coverage often paid as much attention to the ordinariness of the athletes' lives as it did to their extraordinary skill. The cameras focused in on the contenders' families as they gripped their digital cameras and suppressed their anxieties: hence the relentless attention to Michael Phelps's devoted mother and sister. Some of the greatest excitement at the games was generated by the success of athletes with whom the audience could most readily identify, like the 38-year old mother who won the women's marathon. Such footholds for identification are unlikely to be eroded by technological enhancement (2008, p. 24).

What Pistroius is at risk of doing, however, is making spectators unable to relate to the sport they are watching. This is because it is far from clear that Pistorius is competing in the same sport as able-bodied athletes when he runs. In the final section of this chapter I will argue that whether Pistorius is competing in the same sport is the best method for determining whether he should be allowed to compete against able-bodied athletes at the Olympics.

\section{Is Pistorius Competing in the Same Sport?}

Each of the theories for deciding whether certain technologies should be allowed in certain sports so far have had their merits but were ultimately flawed. During my previous discussions I have flirted with the idea that Oscar Pistorius might have an adverse impact on the nature of able-bodied sport itself. In this section I will discuss this notion in more depth. I will argue that the most important consideration when deciding whether he should be allowed to compete against able-bodied athletes at the Olympics is whether Pistorius is different to the extent that he is not competing in the same sport (van Hilvoorde \& Landeweerd, 2008; Jones \& Wilson, 2009). By extension, if a technology alters a sport to the point that the person using the technology in question is no longer competing in the same sport then that technology should be banned.

Some people have expressed their worries that performance-enhancing technologies will lead to past records losing all meaning. David Wasserman 
points out the scepticism that greeted Barry Bonds breaking Major League Baseball's homerun record given that Bonds had been tied to use of anabolic steroids (2008, p. 25). It is possible that there will always be an asterisk next to Bonds' name in the record books. I think the reason for this asterisk's existence can tell us something important about sport. We want there to be some manner of consistency, this is why we enjoy keeping records. We like to compare the past with the present, and we need to make these comparisons within the same sports for them to make any sense. It is interesting to look through the javelin record books and see how the world record has developed; you can compare 2012 with 1912. What is less interesting is to compare the world record in javelin to the world record in shot put. This is because it does not make sense to compare the two different sports. Throwing a long, thin, spear, and throwing a round, heavy, ball, are different activities. There are certain integral aspects that need to be present for a sport to be a sport.

Sometimes enhancement technologies can fundamentally change a sport to the extent that those using the enhancement technologies are not comparable to other athletes. This can be illustrated by the language used in sport. The late 1990 s and early 2000 s in cycling are often known as the doping era. Achievements are often quantified by being described as in the professional era.' This indicates there is something different between two time periods that you should be aware of when making any comparisons.

Sports are defined in certain ways and those competing in them must meet certain criteria. If a competitor does not meet those criteria they should not be able to participate. When I say this I am not talking about all rules. For example; there is a rule in football that all participants must wear protective shin guards, and that those shin guards must be fully covered by the wearers' socks. If a player has his socks pulled down, or is not wearing socks at all, that does not mean that they are not participating in the sport of football. However, if the same player were ride around the field on a horse using the horse to kick the ball into the goal, regardless of how well his shins were covered, they would not be playing the sport of football. It may be an exciting new sport that would take the world by storm, but it would not be football. To 
allow someone to participate in a sport even if they were not meeting the requirements of that sport would be disrespectful to those who are correctly participating in the sport. This is because they have entered the sport on the assumption that their opponents will be doing something comparable, and can be measured by the same criteria. The same is true for the spectators. They have come to see an event on the assumption that they will be viewing certain performances that are associated with their chosen sport. To offer something different would be unfair to them and their interests.

One might object that if the above statement about the interests of competitors and spectators is true then Pistorius is clearly competing in the same sport as other athletes. This could be seen by his status as a media darling. The way he has been embraced by fans and his fellow competitors. As far as his fellow competitors go, the embrace has been far from universal. One of the enduring images from the London Games was eventual gold medal winner, Kirani James, swapping numbers with Pistorius after their race. There have also been questions from athletes sceptical over Pistorius' inclusion, with former Olympic champion, LaShawn Merritt, amongst those showing concern (Kessel, 2012). If we would expect spectators to be upset by something altering the sport that they watch, and Pistorius was participating in a different sport, then it would be expected that there would be public outcry over his inclusion. Yet he is one of the most popular athletes in the world. This objection can be answered by returning to the Sports Incongruity Theory. Pistorius is still new and exciting. He is something unique. So people find him very interesting. If a dozen Pistorius' were to enter the Olympics then the fascination may not be the same. There is also the fact that his popularity has not all been positive. There have been a lot of questions asked over whether he should be competing. Furthermore, there is an inconsistency in Pistorius wanting to race against able-bodied runners if he is not competing in the same sport as them. It would be like saying that you want to take part in an archery competition but turning up with a gun instead of a bow. If you want to compete in a certain sport, then you should not also want to alter the sport and turn it into something different. 
This is the question that should determine Pistorius' Olympic eligibility: When competing against able-bodied athletes, is Pistorius competing in the same sport they are? If he is doing what they are doing, then he should be allowed to continue doing it. If not, then he should be barred from competing in running events against able-bodied competitors. Athletes may employ techniques to gain advantages over each other. Crowds may dislike certain aspects of sports, but the sport itself plays a very important role in all of this and needs to be protected, for the sake of those competing in it and spectating on it.

\section{Conclusion}

It is the purpose of this essay to determine whether Oscar Pistorius should be allowed to compete against able-bodied athletes at the Olympic Games. In order to do this it was important to first decide which framework should be used to determine his eligibility. This was the focus of the first chapter.

I began by looking at the IAAF's 2008 decision to ban Pistorius from competing against able-bodied runners. Their decision was based on the notion that Pistorius' Flex-Foot Cheetah prostheses gave him an advantage. I argued that not only is advantage an inadequate basis for banning someone, but so too is unfair advantage. The reason is that advantages are everywhere in sport, be it financial, geographical, or genetic. To do away with advantages would be to do away with sport as we recognise it.

Following this I discussed Clifton Perry's take on distinguishing between natural and artificial (1983). I contended that Perry's proposed solution, to distinguish between supplementing and exploiting natural ability with technology, is not suited to assessing cases where only one individual has access to the technology in question. As a result it is not well placed to rule on Pistorius' Olympic eligibility. 
Next I applied the treatment-enhancement distinction to Pistorius. I argued that, because the treatment-enhancement distinction is tailored to returning people to a normal level of functioning, it is not a theory well suited to sportspeople. This is because elite athletes are not normal; they represent the extremes of humanity. I concluded that any way of measuring what it is for Pistorius to be normal would be detrimental to either the Olympic or Paralympic movements. The treatment-enhancement distinction cannot cater to the best interest of the sports that the athletes compete in.

In the penultimate section of this chapter I discussed Nick Agar's argument that the spectators are the most important aspect of sport. I denied Agar's assertion that radical enhancement technologies could make us unable to relate to what athletes do. This is because, even if such technology makes us unable to simulate what the athletes are doing, as long as they are still human we will be able to relate to their humanity. Even if the human aspects we relate to manifest outside the sporting arena. I concluded that whilst enhancement technology will never make us completely unable to relate to human athletes, they might make us unable to relate to the sport we are watching and this should be of concern.

I ended this chapter by arguing for what I believe to be the best method for deciding whether Pistorius should be allowed to compete at the Olympics. When considering the use of enhancement technologies, the integrity of the sport should be of the utmost concern. As such, whether Pistorius is competing in the same sport as able-bodied athletes when he runs should be the basis for determining his eligibility. I concluded that if the prosthetic legs used by Pistorius alter the sport of 400m running in the Olympics, then they must be banned. This is because the sport itself should be central to our considerations, as altering the sport affects spectators and participants alike. Athletes choose to participate in certain sports; spectators chose to watch certain sports. To introduce an element that alters what that sport is unfair to all involved. In the next chapter I will investigate several possible methods for determining whether Pistorius is competing in the same sport as his ablebodied opponents. 


\section{Chapter 2: How Do We Decide Whether Pistorius is Competing in the Same Sport?}

\section{Introduction}

It is the job of responsible administrative bodies to preserve the nature of their sport. When the IAAF introduced rule $\mathbf{1 4 4 . 2}$ they should have been worried that reliance on technical aids could alter the nature of athletics to the point that they made the sport unrecognisable. Instead they chose to focus on whether athletes had an unfair advantages over each other, which I have shown above to be the wrong way to look at the problem. As a reminder, rule 144.2 states that:

“... any technical device that incorporates springs, wheels or any other element that provides the user with an advantage over another athlete not using such a device." (International Association of Athletics Federations, 2008, p. 100)

A superior alternative would be "any technical device which adversely alters the nature of the sport will be banned." In the previous chapter I argued that the best framework is to establish whether he is competing in the same sport. The question that now must be answered is: how do we decide what a particular sport is, and how do we determine whether a piece of technology is changing the sport, or causing the athlete using that technology to no longer be participating in a particular sport? In this chapter I will look at different methods that could be used for determining whether what Pistorius is doing is the same as the able-bodied athletes he wishes to compete against. 
First I will discuss the possibility of using scientific testing to determine what it is to run and whether Pistorius meets such a definition. I will offer cricket as an example for how such testing might be used, describing the process used to rule on controversial bowling actions. I will object to solely using biomechanical testing, as it does not have the ability to justify why particular actions are important to a sport.

Following this I will outline Bernard Suits' framework for defining games. I will apply Suits' argument that games are made up of goals, means, rules, and attitudes to Pistorius case. I will argue that Suits' reasoning is ill equipped for dealing with questions of prohibition due to its reliance on the rules. As a result this method encounters similar problems to scientific testing, as it does not answer the question of why those rules exist, and as a result games can be changed without any justification.

Finally I will discuss John William Devine's view that sports are made up of certain excellences and that anything that corrupts these excellences should be prohibited. I will argue that this is the best view for deciding whether Pistorius is competing in the same sport as able-bodied runners as it holds the nature of the sport itself as the most important element for consideration. I will also show that the balance of excellences view has the advantage of catering to the interests of spectators and competitors alike, and as a result it should be adopted for the task of deciding whether Pistorius should be allowed to compete at the Olympic Games.

\section{The Scientific Approach}

One possible option for determining whether Pistorius is competing in the same sport as able-bodied runners is to use scientific testing. In this section I will discuss the possibility of testing whether Pistorius is running in the same way that able-bodied runners are running as a means for determining whether he is playing the same game. I will start by using cricket as a case study, discussing how they introduced testing to determine whether bowlers had 
legitimate actions. I will then describe how a similar process might be applied to athletics. Following this I will investigate some simpler ways athletes could be tested based on their biology. Next I will argue that a scientific approach, while not without its uses, cannot address all the relevant elements of competing in sport. Nor can it define the nature of what it is to take part in a sport. I will conclude that a philosophical approach must be adopted in order to appreciate the true essence of competing in a 400m race, and then decide whether this is what Pistorius is doing when he competes against able-bodied athletes.

There is precedent for such decisions in professional sport being determined by scientific testing. As Carwyn Jones and Cassie Wilson point out, cricket uses science and technology to analyse players' bowling actions (2009, p. 130). The reason for cricket introducing such measures was to solve a problem somewhat similar to the one posed by Pistorius, albeit one that did not involve technological enhancement. Muttiah Muralitharan is a former Sri Lankan international spin bowler with a bowling action unlike any other cricketer to have played the game. Muralitharan (affectionately known as Murali in cricketing circles) was born unable to fully straighten the elbow on his bowling arm; he also has a shoulder with a greater range of external rotation than what is considered normal, and double-jointed wrists. His unusual physiology led to him being accused of having an illegal bowling action. The rules of the game at the time stated that a player must keep their arm straight when bowling, and Murali appeared to bend his arm and throw the ball as he released it. The controversy reached its zenith in 1995 when Australian Umpire Darrell Hair no-balled 5 him 7 times during a test match.

The controversy surrounding Murali's bowling action led to the International Cricket Council (ICC) developing a series of tests to determine whether he was indeed a 'chucker.' The original laws of the game stated that a bowler was not allowed to bend or straighten his arm when delivering a cricket ball. The biomechanical tests that Muralitharan was put through clearly showed that

\footnotetext{
5 A 'no-ball' is term used for an umpire judging a bowler to have delivered the ball illegally.
} No-balls for bending the arm when bowling are almost unheard of. 
there was as much as $12.9^{\circ}$ of flexion in his elbow as he bowled (BBC, 2006). One would assume from this information that he was then banned as he was clearly violating the laws of the game. However, in those tests the control bowlers (bowlers who had "classical" actions that were in no way suspected to be illegal) were also revealed to bend and straighten their arms when they bowled. In fact there has only ever been one bowler biomechanically tested who did not bend and straighten their arm when bowling. 6 This would be the equivalent of running tests on Pistorius only to discover every other elite runner in the world actually had carbon-fibre lower legs. If the ICC were to ban Murali they would have to ban nearly every other bowler in world cricket.

Instead of taking such a drastic step, the game's governing body saw sense (a rare occurrence as I'm sure any cricket follower will inform you) and introduced margins of lenience for bowlers to operate within. They decided bowlers could bend their arm at the elbow up to $15^{\circ}$ when bowling. Murali was tested numerous times throughout his career. Whenever he came up with a new delivery he was always greeted with suspicion, but was always happy to turn his body over to scientists from around the world. He was never once found to exceed the $15^{\circ}$ allowed by the ICC. In 2010, with his very last ball in test cricket, he took his $800^{\text {th }}$ wicket: retiring as the greatest wicket taker in the games' history.

The system used in cricket is not fool-proof. Umpires cannot test players during matches if they suspect them of exceeding $15^{\circ}$ of flexion as they bowl. Nevertheless, it allows for any suspicious players to be tested and banned from competing if they cannot meet the standards laid down by the ICC. Jones and Wilson believe that if scientists can provide detailed analysis of what it is to run then the IAAF can set up guidelines for standardizing what it is to run in events under their jurisdiction. They do, however, express concerns about the effectiveness of such an approach given that no two runners are biomechanically identical (Jones \& Wilson, 2009, p. 130).

\footnotetext{
${ }^{6}$ This distinction goes to West Indian part-timer Ramnaresh Sarwan, who can claim to have to most pure bowling action in cricket.
} 
Even if the biomechanics of sprinting are too complex to quantify (and it seems unlikely that scientists will never be able to provide such information, even if they cannot do it with current technology), a more basic interpretation could be provided. Returning to the previous example, before they had access to technology that could provide in-depth analysis of bowling actions, the ICC defined a legal bowling action as one where the arm did not bend or straighten at all. The IAAF could provide a similarly simple rule that those who wish to compete in the Olympics (or IAAF sanctioned competitions) must be physiologically intact.

There are problems with this approach. If the ICC were to ban Murali for bending his arm despite the fact that $99 \%$ of bowlers bend their arms, then this would seem to be a very inconsistent and unfair way of dealing with the problem. Is it unfair, though, if the ICC simply did not know that all bowlers were bending their arms? As soon as they realised that all bowlers did it they adjusted the rules so that bowlers would only be banned if they bent their arm an unnatural amount. Similar problems could arise with a rule stating runners must have intact bodies. What if a runner has had his appendix out? Should he be banned from running? It may seem obvious that such an issue as a missing appendix has no bearing on how someone runs, at least not in the way that running on prosthetic limbs would. Although a person without an appendix is presumably lighter than a person with an appendix. A few grams could translate to a hundredth of a second, which can be the difference between a spot on the medal podium and four more years of asking 'what if?'

But all runners are of different weights and sizes. The key is that the appendix does not change the nature of the sport, whether it is present or not. Just as having an absentee appendix would not change a bowler's action in a cricket match. It would seem very strange to say that an athlete is competing in a different sport on the basis of them not having an appendix. Not having legs has more bearing on the way some one runs than the absence of any other appendage. So perhaps a rule simply stating that in order to compete in the Olympics runners must have intact legs would solve this issue, but this once again would create difficulties. Most sprinters shave their legs to make 
themselves more streamlined. Are shaved legs intact? What about an athlete who is missing a toe? It wouldn't seem that they are running in a manner as different to other athletes in the way that Pistorius is. The key difference seems to be the use of prosthetic legs. Perhaps if an athlete with a missing toe used a prosthetic one to compete we would have the same suspicions about them as we do about Pistorius.

Biomechanical testing is one way we might be able to measure whether Pistorius is running in the same way that other athletes are, and may play an important role. However, this fails to get to the heart of why such decisions are important. It might be able to tell us how much force a runner is exerting and how much energy is being expended, but it cannot tell us whether this alters the nature of the sport in question. This is the advantage of philosophical testing; it can give a reason why it is important that a bowler does not bend their arm more than 15 degrees when they bowl. Fortunately philosophical testing does not require a multimillion-dollar sports science facility. Instead, all that is required is an armchair. Below I will discuss reasons for excluding Pistorius on the basis that he does compete in the same sport as other athletes from a philosophical perspective.

\section{The Suitian Framework}

When deciding whether Pistorius is competing in the same sport as ablebodied runners, a reasonable place to start might by deciding whether he is running. If this is the place to start, then the first question to be answered here is: what is running? It is a question that when asked seems simple, but trying to find a simple answer to it is not so easy. Bernard Suits, a pioneer in the discipline of the philosophy of sport, offers a comprehensive outline of how we might define any given game. Below I will outline Suits' framework before applying it to Olympic 400m running. I will then discuss how this might relate to Pistorius competing at the Olympics. I will conclude that Suits' definition of games is not helpful in deciding how Pistorius runs as it is too reliant on the rules of the game without taking into account justifications for why those rules exist. 
Bernard Suits' is one of the founding fathers of the philosophy of sport. His definition of what it is to play a game is broken up into four parts:
1. The Goal
2. Means
3. Rules
4. Attitude (1978, pp. 36-38)

Suits describes the goal of a game as a "specific achievable state of affairs", this can be otherwise stated as the most basic goal of any given game (1978, pp. 36-37). For example the goal of golf is to get the ball into the hole.

Means are the methods that are permitted to achieve the goal (Suits, 1978, p. 37). To continue with the example of golf, the means of getting the ball into the hole are to hit it with golf clubs.

The rules, states Suits, "set out all the conditions that must be met when playing the game" and describe the means that may be used in order to achieve the goal (1978, pp. 37-38). The rules of golf state that one must not throw the ball into the hole, they must use clubs in order to do so, and those clubs must be within specific dimensions. If one breaks the rules they are no longer playing the game. Even if a person is on a golf course, attempting to get a golf ball into a hole, while dressed in somewhat ridiculous clothing, if that person is trying to throw the ball into the hole then, whatever it is that they are doing, it is not golf.

The final concept that Suits uses to illustrate what it is to participate in a game is attitude. He describes attitude as an acknowledgement of the game that is being undertaken and the rules that govern it (Suits, 1978, p. 40). To continue with the golf analogy, golfers accept that that they are playing golf within a set of established rules with the aim of hitting a ball into a hole. This differs from people who might happen to be hitting a ball into a hole with golf clubs, and happen to be playing within the rules of golf, but their undertaking is not with the intent to play a game of golf. They lack the attitude of a golfer. 
If we now apply Suits' definition of what it is to play a game to Oscar Pistorius' discipline of choice, $400 \mathrm{~m}$ running, we can establish what it is to run $400 \mathrm{~m}$ at the Olympics. We can then endeavour to discover whether this is what Pistorius does when he runs a $400 \mathrm{~m}$ race.

The goal of a 40om race is to cross the finish line ahead of your competitors. The means of doing this is to run in your allocated lane. The rules of competing in a 400m competition, particularly at the Olympics are far too complex to be summed up in a sentence, but they involve things you would expect. For example, rules such as the prohibition of intentionally tripping your opponents, and waiting for the gun to go off before leaving the starting blocks (International Association of Athletics Federations , 2008). The attitude of a 40om runner is one of doing all of the things listed above in order to compete in a race.

Pistorius, I think it is uncontroversial to say, meets the goal of a $400 \mathrm{~m}$ race; he is certainly trying to cross the finish line ahead of his competitors. He also seems to be using the means of a 400m runner by running in his lane. He is obeying the rules (as Weyand et al. proved when they overturned his IAAF ban). And, he clearly has the attitude of a man who wants to race over $400 \mathrm{~m}$, without it he would not be where he is today.

But whether he is running is not cut and dried. In athletics the 40om is sport based on running, so if Pistorius is not running it is a problem. As Jones and Wilson point out, if he is not running then whatever he is doing when competing in a 40om race should not be allowed, even if it is allowed in another game: T 44/43 400m (2009, p. 129). Perhaps a solution could be found Suits' definition of games could be applied to running as an action. This, however, would not be very helpful as Suits framework are designed to describe conventional practices, and the act of running itself is not a conventional practice. So Suits' definition of games alone cannot help us decide whether Pistorius is playing the same game as the able-bodied athletes he competes against. Perhaps it could be combined with the scientific 
approach given above, taking the best of science and adding the best of philosophy. Indeed that may be the correct approach but I do not think that for this particular task Suits' definition of games is the best of philosophy.

The biggest limitation with using Suits' framework for making decisions regarding prohibition is the fact that the rules of the game hold a great importance. Certainly rules are important in sport, but as administrators can change the rules with the stroke of a pen and a rubber stamp so can facts about whether someone is playing a game or not. There is not necessarily any moral weight to such decisions decision, there is no reasoning given to why the rules exist. While a helpful guide at the beginning of the search for how we can decide whether Pistorius is playing the same game as able-bodied athletes when he runs, Suits' guidelines are ultimately too limited. In the final section of this chapter I will outline what I believe to be the best method for deciding whether what Pistorius is doing when he runs $400 \mathrm{~m}$ is significantly different to what able-bodied runners do: deciding whether he maintains the balance of excellences of $400 \mathrm{~m}$ running.

\section{The Balance of Excellences}

I previously discussed how we define games, and how we might define $400 \mathrm{~m}$ running. This is important because if Pistorius is not playing the game of 40om running then he should not be able to compete at the Olympics. The question that must be answered is how we assess whether he is playing the same game. Above I discussed how we might define what it is to play the game of 40om running, using framework defined by Bernard Suit. While this was a natural place to start when evaluating what $400 \mathrm{~m}$ runners look to achieve, the Suitian framework does not do enough to get to the heart of what an Olympic $400 \mathrm{~m}$ race is tailored to display (the essence of Olympic 40om running if you will). In this section I will advance what I believe is the best method for deciding whether what Pistorius is doing when he runs $400 \mathrm{~m}$ is significantly different that he should be excluded from able-bodied competition. This method is John William Devine's balance of excellences model of sport. Devine argues that sport is fundamentally about striving for excellence, and 
that essence of sport is the pursuit of certain excellences. Different sports constitute different excellences that must be achieved in order to do well in competition. Devine calls these the balances of excellences. In his 2010 article Doping is a Threat to Sporting Excellence he argues that performance enhancing drugs should be banned if they upset the balance of sporting excellences (p. 637). In the following section I will discuss Devine's balance of excellences theory. I will argue that it is best suited to ruling on whether certain enhancement technologies should be allowed because it is tailored to preserve the important aspects of a sport. I will demonstrate that the balance of excellences theory has the key advantage of allowing sports to progress technologically while ensuring that they do not lose their identity. I will also show that the balance of excellences approach not only helps preserve the identity of sports for the sports sake, but also for the sake of the spectators, and the competitors. I will conclude that it is the best framework for deciding whether Oscar Pistorius is competing in the same sport as able-bodied runners, and as a result whether he should be allowed to compete at the Oympics.

The balance of excellences theory has its grounding in the fact that sport rewards its participants for excelling in a variety of areas. Different competitors have different strengths. However, if one area of strength becomes dominant over another area then Devine believes that the balance needs to be redressed. The balance can be restored either by banning whatever has caused one excellence to become unreasonably dominant, or by introducing another factor into the sport that allows the other excellences to catch up. He uses the example of the introduction of tennis rackets made of fibreglass that led to power serving becoming the dominant excellence in men's tennis to outline his point:

[I]n the late 1990s, the men's singles tennis championships at Wimbledon was criticised as being dominated by powerful serving. While this may partly have been a complaint about the spectacle of tennis losing some its appeal for fans, it can also be understood as a complaint that one type of excellencepowerful serving-assumed too much prominence in the style of tennis that 
prevailed at the time. That is, while the rules of tennis still allowed for the display of all the excellences valued in tennis, developments in the bio mechanics of serving and advances in racket technology meant that the contribution of different excellences to the outcome of competition shifted in such a way that one excellence came to dominate, and others, such as deftness of touch and patient strategic play, no longer made a significant contribution to the performance of those who were successful in the sport. In response to these criticisms, tennis authorities changed the court surface and pressure of the balls to encourage the longer, more strategic rallies that were seen to be missing from competition. These measures might be best explained as an attempt to redress the internal relationship between the excellences around which the sport is organised (2010, p. 638).

While Devine's use of the balance of excellences is very general in its application, it can be tailored to specific sports to help get to the heart of why a certain sport exists. By showing what excellences certain sports are tailored to express we can decide whether someone is maintaining those excellences and, as a result whether they are competing in the sport. It might seem that the balance of excellences approach promotes stagnation and as a result does not fit in the ever-changing world of sport. Such a view is mistaken. Rather than restricting change a balance of excellences view helps ensure that changes do not corrupt the nature of the sport, and this is one of it's key advantages over other theories. This can be seen by returning to Devine's tennis example. Rather than endorse banning carbon fibre tennis rackets for upsetting the balance of excellences in tennis, all that was required was to redress the balance of excellences by altering another factor: the balls. This allows for sports to evolve but keep their identity. It makes it an ideal theory to move forward and address new challenges, like prosthetic limb technology that allows athletes to run qualification times for the Olympics.

One might question why the excellences that sports are tailored to show are so important. The reason the excellences are so important is that they are what give sport their diversity and identity. In the previous chapter I discussed Agar's view that the spectators are the most important aspect of elite sport. If this is true then the balance of excellences view gains another ally as 
spectators are drawn to certain sports because they want to see certain things, these things are the excellences that sports bring out of competitors. People don't go watch football matches to see how good players are at running with the ball in their hands, that is why players are not permitted to use their hands (with the exception of goal keepers). Handling the ball is not an excellence that football exists to exploit. If crowds wanted to see players using their hands they would watch rugby. Therefore it is in the interests of the spectators to preserve the balance of excellences of sports otherwise they will not be watching the same sport.

In the first chapter I also discussed unfair advantages in sport; a theory tailored to preserving equality for those competing in the sport. The balance of excellences view is also a friend of equality. If an individual introduces a technique or piece of equipment that tips the balance of excellences so that they are no longer playing the same sport then there is inequality, as those involved are not playing the same sport. It is not to say that one has an advantage, it is to say that they are not comparable. Someone throwing a javelin does not have an advantage over someone throwing a shot put; they are completely different sports designed to display different excellences. While they have the same goal: throwing an object as far as possible, they are unequal and incomparable as they employ different methods to throw different objects. The balance of excellences view ensures that everyone is equal as it ensures they are all competing in pursuit of the same excellences.

Devine used his balance of excellences argument to contend that performance enhancing drugs should be banned. For the reasons I outlined above, I believe that it is the best theory for dealing with Oscar Pistorius' eligibility for the Olympic Games. It is a theory that has the best interest of the sport at heart. It allows preservation of the key aspects of any given sport without causing stagnation. It is also a theory that indirectly caters to the spectators by ensuring that the sport they choose to watch does not become unrecognisable. The balance of excellences view also ensures that competitors are competing on an equal playing field, by ensuring that that those competing against each other are displaying the same excellences. 


\section{Conclusion}

In the initial chapter I investigated several different methods for deciding Pistorius' fate. I argued that the best approach was to assess whether he competes in the same sport as able-bodied competitors when he runs. The second chapter was dedicated to examining how we might decide whether Pistorius is competing in the same sport as his able-bodied counterparts.

I began the chapter by assessing whether scientific testing alone could determine if Pistorius was competing in the same sport as able-bodied athletes. I offered cricket as a blueprint for how biomechanical testing might be used to assess what it is to run. I concluded that scientific testing alone was not enough to determine whether Pistorius was doing the same thing as ablebodied athletes. This is because it cannot tell us why it is important that runners move within certain parameters. I then moved onto possible solutions from philosophy.

The first philosophical solution I looked at was Bernard Suits' definition of games. I argued that Suits' definition of games was not particularly well suited to ruling on the prohibition of certain elements in sport. This is because of the importance that the rules of the sport play in Suits' definition. Just as biomechanical testing fails to take into account why the actions of athletes should fall within certain parameters, Suits' framework fails to take into account why certain rules exist. Suits does not require any moral justification for the existence of rules, merely that they exist.

I ended the chapter by stating what I believe to be the best system for determining whether two athletes are competing in the same sport: the balance of excellences. I argued John William Devine's view that sports are made up of the pursuit of certain excellences is best equipped to deal with controversial cases of technological enhancement. This is because it preserves important aspects of sport: the pursuit of excellences for which the sports exist. It also prevents undesirable change without causing stagnation. I 
concluded that whether Pistorius is allowed to compete at the Olympics should be decided by whether he maintains the balance of excellences of 40om running. If he does not, if his prosthetic legs tip the balance of excellences to the extent that he is not competing in the same sport as ablebodied athletes, then he should be prohibited from competing against them. In the final chapter of this essay I will establish the balance of excellences of Olympic 40om running. I will then examine whether Pistorius maintains the balance of excellences. Finally I will discuss the implications for Pistorius' Olympic and Paralympic eligibility. 


\section{Chapter 3: The Balance of Excellences}

\section{Introduction}

In the first chapter I argued that the best way to establish whether Pistorius should be allowed to compete against able-bodied athletes at the Olympics was to decide whether he was competing in the same sport. In the second chapter I gave reasons why the best way to decide whether Pistorius was competing in the same sport as able-bodied athletes is to assess whether he maintains the balance of excellences in Olympic 40om running.

I will start by applying the balance of excellences to two recent controversies in golf involving the use of technical aids that threatened to alter the sport. This section will show the strength of the balance of excellences view when dealing with real world scenarios.

I will discuss what the balance of excellences in Olympic 40om running might be. I will outline what I believe to be three very broad and uncontroversial excellences that make up the sport: going fast, using your body to propel yourself around a track, and exploiting technical aids. I will compare 400m running to Formula 1 racing which shares the same basic excellences to show the importance of the weight that each excellences has, and as a result why it is important to maintain the balance of excellenes.

After setting out the above excellences I will apply them to Pistorius. I will argue that he tips the balance of excellences too far in favour of exploiting technical aids, to the extent that he is participating in a different sport than the able-bodied athletes he wishes to compete against. As a result of this I will 
conclude that Pistorius should not be allowed to compete against able-bodied athletes at the Olympics.

Following this I will look at the implications for Pistorius' Paralympic career. Using the balance of excellences argument I will examine whether he and other double amputee athletes should to compete against single amputee athletes, as is currently the case. I will argue that that, as with the Olympics, the two sets of athletes do not display comparable excellences when competing.

\section{Golf and Case Studies in the Balance of Excellences}

In the previous section I established that the balance of excellences account of sport is the best theory for establishing whether a piece of enhancement technology should be allowed in a certain sport. In this section I will further establish the strength of the balance of excellences model by applying it to real world scenarios. I will do this by looking at two cases in recent sporting history where rulings were made on whether to prohibit certain practices or devices in order to maintain the integrity of the sport and apply the balance of excellences theory to them. This section will show the ability of the balance of excellences to be applied on a case-by-case basis. I will discuss two examples from golf, which on the surface might seem similar but had two very different outcomes: the case of disabled golfer Casey Martin, who was allowed to use a golf cart in PGA Tour events. I will argue that this is the correct decision on the balance of excellences view as walking between holes is not an important excellence in golf. I will then look at the decision to ban long-handled putters. I will show that long handled putters were rightly banned as they tipped the balance of excellences in putting by diminishing the importance of the ability of golfers to keep a steady hand.

In their article Convention and Competence: Disability Rights in Sports and Education, Anita Silvers and Davids Wasserman (2000) discuss the plight of American golfer Casey Martin. They discuss whether Martin should have been 
afforded a dispensation to use a golf cart in tournaments despite it being against the rules. Martin suffers from Klippel-Trenaunay-Weber Syndrome, which restricts the flow of blood to his right leg. This impairment makes him unable to walk the 18 holes required to play a round of golf. This was a problem for Martin, who turned professional in 1995, because the Pro Golfers Association (PGA) does not allow the use of golf carts in PGA Tour events. As a result, Martin sued the PGA in the Supreme Court for the right to use a cart under the Americans with Disabilities Act (ADA). The lawsuit addressed Title III of the $\mathrm{ADA}$, which meant that in order to rule the Court needed to determine:

(1) whether the requested modification was a reasonable one,

(2) whether it would fundamentally alter the nature of the competition (Silvers \& Wasserman, 2000, p. 63).

The court found that the request to use a cart was a reasonable one. Golf carts are not in short supply, and no modifications would need to be made to the courses in order to accommodate a cart as they are regularly used by weekend golfers. The issue upon which the decision rested was whether Martin's use of a golf cart would fundamentally alter the nature of the PGA Tour. The PGA argued that walking was a fundamental part of the tour, and called upon some of the greats of the game to testify that battling the fatigue that accrues from of walking 72 holes over four days for a tournament is part of the battle, and that any use of a cart would give that particular competitor an advantage (Charlish \& Riley, 2007, pp. 941-42).

It is certainly true that Martin using a cart has a great advantage over another version of himself not allowed to use a cart. Nevertheless the Court made its decision not based on whether Martin would gain an advantage when compared to his performance without a cart. Rather, the Court chose to assess whether Martin would gain an advantage, either psychologically or physically, relative to other competitors if were allowed to use a cart. The Court found that as Martin suffers significant pain when he walk, as well as when he gets in 
and out of a cart, and risks serious injury by competing, the psychological and physical stress that he undergoes while playing in a tournament more than matches that of able-bodied competitors (Charlish \& Riley, 2007, p. 942). The Supreme Court ruled that Martin was allowed to use a golf cart while competing on the PGA tour.

While the Supreme Court had a reasonable amount of focus on the advantage aspect of Casey Martin's request, the framework through which they were looking at the nature of the advantage was whether it would fundamentally alter the nature of the competition. It is undeniable that in many cases where the balance of excellences is tipped one way or another there will also be an advantage to the athlete whose actions are responsible for the tipping. However, the important factor is that the advantage should not be the focus of the decision to ban the athlete, as I showed in the first chapter questions of advantage are not a good way of looking at such scenarios. It is the integrity of the sport that should be in focus.

I will now look at how Martin's plight might have been viewed if the Supreme Court had adopted a Balance of Excellences view of sport in order to determine Martin's eligibility for the PGA Tour. It might be tempting to view Martin's case in a similar way to Pistorius' case and discuss the exploitation of technical aids. This would be a mistake, not because golf is a sport in which the exploitation of technical aids is a dominant excellence, but because the technical aid in question, the golf cart, does not affect the process of hitting a golf ball, or judging the length of a putt.

The key excellence that is in question seems to be one of fitness and endurance. As the PGA Tour testified, battling the fatigue of walking 72 holes is part of the PGA Tour and Martin would not have to do that (Charlish \& Riley, 2007, pp. 941-42). It certainly does not seem to be a dominant excellence in golf; it would seem strange to say that those who use a cart to get around the course for a Sunday morning game with friends are not playing golf. Nevertheless, perhaps it could be said that it is not PGA Tour golf, where 
battling fatigue could be seen as an added excellence, along with dealing with the pressure of huge crowds and large amounts of money being on the line.

Martin, however, does not remove the excellence of battling the fatigue of playing 72 holes; he must still go through it. Given his disability he probably has to battle fatigue more than most. So Martin using a golf cart does not seem to tip the balance of excellences or change the sport. There might be two objections to my reasoning. The first, that this means anyone who claims to be less fit than other golfers could request the use of a cart on the basis that it will keep the balance of excellences in check. To this I have no rebuttal. An obese golfer may want to use a cart on the PGA on the grounds that he still has to battle fatigue as much as a young fit golfer who walks.

This leads to a second objection: that it allows special treatment for certain individuals which seems to go against our general views about discrimination and a desire to see a level playing field. Once again I'm happy to concede this point. The reason for this is that it does not seem that fitness, endurance, and battling fatigue are important enough excellences in golf to ban the use of golf carts for any players on the grounds that they alter the nature of the sport. One only needs to look at obese, chain smoking, alcoholic, and double major winner, John Daly to see that many Golfers are far from supreme athletes. The ability to walk 72 holes over 4 days is not nearly as important as the ability to keep a steady hand, and a pure swing, for example. It could be argued that the fatigue of walking 72 holes effects concentration and ability to keep steady and focused, but consider the following:

- It is recommended that for health benefits the average person should take 10,000 steps per day (Bohannon, 2007, p. 1643).

- Given that the average persons stride length is 2.5 feet long, 10,000 steps is roughly 5 miles.

- The average golf course in America is 7,200 yards (just over 4 miles) long.

There are a few caveats that must be added to the above facts. First of all the distances measured to determine the length of a golf course is from the tee to the pin, so it does not include the distance between holes, or any additional 
distance for wayward shots. Even when the additional distance is taken into consideration it seems quite difficult to imagine that golfers who are the elite in their sport are significantly fatigued by walking roughly same distance as it is recommended an average adult walks each day. Walking is not a significant part of the competition. As Silvers and Wasserman point out in their discussion of the Martin case: if a player walks the course faster than his rivals he does not get given a lower score for the round, nor is there any minimum allowed time for traveling between holes or completing a round (2000, p. 65). Banning the use of carts in golf because players need to walk between the holes makes about as much sense as banning steroids in chess because players need to lift the pieces.

A more recent example of controversy in golf is the prohibition of longhandled Putters. With a traditional short-handled putter the club is held away from the body, floating in the void between the player and the green. This means that a golfer has to be in complete control of their arm movements when putting. The slightest variation can send the ball off course. The longhandled putter, on the other hand, is anchored to the players' body. What this means is that the top of the club is pushed up against the body of the person holding it (either against the chest or the belly). This means that the club will move around less as it is swung due to the wrists having less control over the putters movement which, in theory, will allow for more accurate putting.

The ability to putt is a key excellence in golf. Championships are won and lost on the green. Even if long-handled putters make putting easier the user still has to make their putts, so the excellence of putting isn't eliminated in anyway. However, an argument can be made that long-handled putters eliminate a key excellence in the act of putting: keeping the wrists and hands steady. Players need nerves of steel to hole key putts at major championships, they need to control every element of their body. Having the putter anchored to the body means that their is less emphasis on controlling the hands and wrists. Having a long-handled putter doesn't mean that the user will make every putt, but a key excellence is lost, the excellence of controlling the wrists and hands in pressure moments. This has always been a part of golf, and it 
would be a shame if it were lost. Long-handled putters make the excellence of keeping arms steady far less important so banning them was the correct decision.

This section has been used to further display the how the balance of excellences works with technical aids in sport. By applying the balance of excellences theory to two recent instances of technology threatening to fundamentally alter the sport of golf I have been able to show the qualities of the balance of excellences view in real world scenarios. I will now apply the balance of excellences to the case of Oscar Pistorius.

\section{The Balance of Excellences of 40om Running}

If the balance of excellences argument is going to be used to assess whether Pistorius is allowed to compete in the Olympics then we must first establish what the balance of excellence of $400 \mathrm{~m}$ running is. In this section I will begin by describing the three most basic excellences of Olympic 400m running: To go fast, to use your body to propel yourself around a track, and to exploit technical aids. I will describe why it is not just the excellences that are important but the balance of excellences by comparing Olympic 40om running to car racing, which shares the same excellences. I will use this comparison to outline the why it is the relationship these excellences have that is important, by illustrating that the balance is so different amongst the two sports.

When establishing what the excellences that Olympic 40om running is tailored to display it might be tempting to be overly specific. However, as is often the case, a more simple approach is better. This is because it is less controversial; the more one tries to get to the nuances of running, the greater the margin for error. After all, $400 \mathrm{~m}$ running is quite a simple sport. I propose that at their most basic the excellences that $400 \mathrm{~m}$ runners seek to display are:

1. To go fast

2. To use their body to propel themselves around a track 


\section{To exploit technical aids}

As I said above, this is a very basic and very broad list, it may be true that there are more nuanced excellences involved in 400m running. I have chosen these excellences because they are simple, easy to understand, and relatively uncontroversial. It may seem strange that I have included the third option on this list. However, until athletes compete naked (or at the very least shoeless), without the use of starting blocks, and without the rubberised artificial track they run on, they need to exploit technical aids in order to compete in a race.

One might object that the excellences I have outlined above are too broad. It could be argued that, while they apply to Olympic running, they also apply to other sports that are completely different: motor racing for example. It is true that those who compete in motor racing are trying to go fast. They also use their body to exploit the technical aids at their disposal (a Formula 1 car for example) in order to propel themselves around a track. Indeed it seem that these excellences will be applicable to any sport that involves racing.

That sports share the same or a similar set of excellences does not mean they are the same sports, it is the balance struck between those excellences that is important. Olympic 40om racing may have the same broad excellences as Formula 1 racing but the balance of those excellences that competitors must display is completely different. Exploiting technical aids is vastly more important for Formula 1 drivers than it is for Olympic runners. Similarly, the excellence of using their body to propel themselves around a track is vastly more important for Olympic Runners than it is for Formula 1 drivers. This is not meant to belittle the important skills that runners use when pushing out of the starting blocks and getting a good grip on the track. Nor is it meant to undersell the physically exhausting task of driving a high performance race car around a track. What it is meant to show is that the weight that these excellences have reflects important features of each sport.

If I were to line up at the start of an Olympic 400m race in a car I would not be allowed to compete, as I would not be exhibiting the same excellences as 
the other competitors. I would have tipped the balance of excellences too far in favour of the ability to exploit technical aids. This is because my technical aid (the car) would be doing so much more work in the race than the technical aids of my fellow athletes (their shoes). Such would be the extent of the difference in the excellences that we were displaying it could no longer be said that we were competing in the same sport. I will now argue that the same is true of Pistorius when he competes against able-bodied athletes.

\section{Does Pistorius Upset the Balance of Excellences}

Now that I have applied Devine's balance of excellences theory of to Olympic 40om running, I will assess whether Pistorius and his carbon fibre blades upset the balance of excellences that make up Olympic 40om running. In this section I will argue that Pistorius does upset the balance of excellences of Olympic 40om running. I will go through each of the three excellences outlined in the previous section and argue that while he maintains the first excellence (to go fast), the same cannot be said with any certainty about the second excellence (using his body to propel himself around a track), and definitely cannot be said about the third excellence (exploiting technical aids). As a result Pistorius tips the balance of excellences too far in favour of exploiting technical aids and cannot be said to be competing in the same sport as able-bodied athletes. I will conclude that what Pistorius is doing when he runs is the sport of T43 40om running, which is not comparable to Olympic $400 \mathrm{~m}$ running.

Above I established the three most basic excellences of $400 \mathrm{~m}$ running at the Olympics:

1. To go fast

2. To use their body to propel themselves around a track

3. To exploit technical aids

For able-bodied runners the second excellence has by far the most weight to it, with the third excellence of far lesser importance. I will now assess Pistorius in 
terms of these three excellences. The first excellence does not pose a problem to Pistorius. By virtue of running under the Olympic qualification time Pistorius is undoubtedly a very fast $400 \mathrm{~m}$ runner. There is a reason he as earned the nickname the fastest man with no legs.

The second excellence outlined above is more problematic. Pistorius uses his body to propel himself around the track. His legs are not remote controlled. Without considerable input from his upper legs and the rest of his body he would not move, but as I mentioned earlier, it is the balance of these excellences that is important. If Formula 1 world champion, Sebastian Vettel did not use his body his million-dollar car would not move either. The key question is to what extent Pistorius uses his body to propel himself around the track. It would seem that it is different to the amount that able-bodied runners use their body when running.

When Kirani James won Grenada's first Olympic medal by taking gold in the men's 400m in London he was not only using his body. He was wearing specialised track shoes. It does not take extensive scientific testing to measure the different amount that Pistorius, Vettel, and James are using their bodies. All that is required is some imagination. Consider the following:

A. Oscar Pistorius running around a track on his carbon fibre Flex-Foot Cheetahs. Sebastian Vettell driving round a track in his Red Bull sponsored Formula 1 car. Kirani James running round a track in his florescent yellow Nike track shoes.

B. Now consider the same scenario again, but this time Pistorius does not have his carbon fibre blades, in fact he does not have any form of prosthetic legs. He is merely propelling himself around a track as best he can using only his stumps. Vettel has also been stripped of his technical aids. He is now propelling himself around a track the best he can with the tools at his disposal: he is running. Finally consider James, without shoes, as naked as the day he was born, running around a track.

The disparities between scenario A and scenario B illustrate the different extent that each athlete is displaying the excellence of using their body to propel themself around a track. What Pistorius and Vettel are doing in scenario B differs greatly from what they are doing in scenario A. Whereas 
what James is doing in the two scenarios is barely any different. This shows that James is using his body to propel himself around the track in a far different way than what Vettel and Pistorius are doing. The reason for this difference comes from the third excellence: the ability to exploit technical aids.

As well as showing the different ways in which each of the three athletes discussed use their bodies to propel themselves around a track, the above scenarios showed the extent to which each athlete relies on technical aids. When Pistorius and Vettel are stripped of their technical aids in scenario B, what they are doing becomes completely different. The same cannot be said about James, because the ability to exploit technical aids plays such a small role in able-bodied 40om running: as far as the balance of excellences goes, the ability to exploit technical aids does not have much weight. While Pistorius may not rely on exploiting technical aids to the same extent that Vettel does, it is still extremely important to him. Without his blades he is doing something completely different. If you watched James run with shoes then run without shoes the difference would not be drastic, indeed you might not notice any difference at all. This shows that Pistorius' reliance on exploiting technical aids is far greater than any able-bodied athlete. As a result he tips the balance of excellences of 40om running too far in favour of exploiting technical aids.

One might take issue with my inclusion of exploiting technical aids in the excellences of 40om running. Perhaps the above thought experiment shows that exploiting technical aids is not an excellence in 40om running as there is negligible difference between James with technical aids and without technical aids. I disagree.While it is not a major excellence, exploiting technical aids is still an excellence that exists in any sport where technical aids are present. The importance of the ability to exploit technical aids is what differs. However, even if this were true it does not aid Pitstorius as all it means is that he is introducing a completely new excellence into the sport. This would also have the consequence of him altering the sport of Olympic 40om running, and not competing in the same sport as athletes like James. 
In the previous section I mentioned that one of the strengths of the balance of excellences was that it allowed sport to move forward. It can do this by redressing the balance of excellences by introducing counter measures where it could, rather than just banning the cause of the initial imbalance. So rather than just ban Pistorius is it possible that something else could be introduced that could just redress the balance of excellences? After all tennis managed to to counteract the speed of carbon fibre tennis rackets by introducing softer balls. It is difficult to think what such a counter measure might be. One possible solution is providing all runners with shoes that allow them to alter the way the move so that the ability to exploit technical aids becomes as great for them as it is for Pistorius. This, however, would not solve anything, as it would just mean that every runner was competing in a sport different to Olympic 40om running. The fact that exploiting technical aids plays such a small role is very important to the sport. Pistorius has tipped the balance of excellences of Olympic 40om running too far in favour of exploiting technical aids. Any countermeasure would need to make drastically increase his reliance on his body to propel himself around the track so that his reliance on technical aids became as minimal as Kirani James' reliance on his running shoes. This seems like it would be an impossible task, as no matter what was changed as long as Pistorius was wearing prosthetic legs, his ability to exploit them will play a very important role in his ability to run.

If we return the two examples from golf used to explain the balance of excellences at the beginning of this chapter we can see the key difference between the Pistorius case and the Martin case. Pistorius is making a small excellence extremely influential to the extent that he changes the sport of running, whereas Martin is making a small excellence less influential but in a way that does not alter the sport of golf. A similar case in running would be if a runner were to compete without shoes, like the famous British runner Zola Budd often did during the 1980s. Such a runner would be lessening the excellence of exploiting technical aids as they would not need to exploit the technology in their running shoes. Such a move may alter the balance of excellences in other areas with regard to injuries, or sponsorship, but the balance of excellences would not be altered to the point that the sport would 
be changed. Not all athletes will exploit the excellences of a given sport in the same way, people play to their strengths. Just because two athletes display excellences differently does not mean that they are competing in different sports. It is just when the balance of excellences is tipped to the point the sport is fundamentally altered that the balance must be addressed.

In the case of long-handled putters, on the other hand, the similarities with the Pistorius case are there to be seen; something new was introduced that altered a key excellence of the sport to the extent that it changed the nature of the sport in a significant way. As a result the decision was made to ban this threat to the nature of the sport. This differs from the Martin case as walking between holes is not an important excellence in golf.

In this section I have applied the balance of excellences of Olympic 40om running to Oscar Pistorius. I have shown that, while he maintains the first excellence of going fast, he fails to maintain the balance of the second two excellences: using his body to propel himself around a track, and exploiting technical aids. This is due to his reliance on prosthetic legs to be able to run. This means that when he runs Pistorius is not competing in the sport of Olympic 40om running. He is competing in a different sport. He is competing in a sport where the ability to exploit technical aids is a key excellence. He is competing in a sport called $\mathrm{T} 43$ 40om running, which is a sport that can be found at the Paralympics. The two sports display the same excellences but they are far differently weighted, and as a result they are not comparable.

\section{Paralympic Implications}

In the previous sections I explained why Pistorius should not be allowed to compete against able-bodied athletes at the Olympics. This is because the excellences an athlete displays when running 400m with intact legs are different to the excellences that an athlete displays while running $400 \mathrm{~m}$ on prosthetic legs. This is mainly due to the different weighting that the ability to exploit technical aids has for the different sets of competitors. This is an 
important point. What able-bodied runners and amputee runners are doing is different. So different that it is not comparable. When an amputee runner like Pistorius is running one of the key excellences he must display is mastery of his prostheses. This is not an excellence that is sought in able-bodied 40om running. It is the same reason that an able-bodied runner should not be allowed to compete at the Paralympics. Able-bodied runners do not display the relevant excellences that are at the core of Paralympic running. The two are not comparable. The above conclusion raises questions about Pistorius' participation in the Paralympics. If we are to assess whether he should be able to compete at the Olympics on grounds of the balance of excellences then it is only fair that we apply a similar assessment to his Paralympic eligibility. In this section I will argue that it is not only in the Olympics that Pistorius' disability alters the balance of excellence in running. I will argue that, just as the excellences displayed by double amputee and able-bodied runners are not comparable, nor are the excellences displayed by double amputees and single amputees.

According to the Paralympic classification system Pistorius is categorized as T43: double below the leg amputation. Unfortunately due to lack of competition from other $\mathrm{T} 43$ athletes, he runs in the $\mathrm{T} 44$ category. $\mathrm{T} 44$ athletes have a single below the knee amputation. It might seem like an advantage to have one intact leg as opposed to no intact legs. However, those in the T44 class have complained about having to compete against double amputees because his double amputation allows him to have a more even stride (Bainbridge, 2012). In T44 running, the ability to maintain an even stride between your prosthetic leg and your intact leg is clearly an important excellence. Pistorius does not have to worry about this excellence. Undoubtedly he encounters difficulties from having a double amputation that those with a single amputation do not encounter. However, the fact they face different difficulties when running means that the balance of excellences for $\mathrm{T} 43$ running is different from the balance of excellences for $\mathrm{T} 44$ running. That is why they are categorised differently. 
If you were to add a single amputee to the thought experiment from the previous section you would clearly see that what Pistorius and a single amputee were doing without their technical aids would be very different. This shows that there is a clear difference in the weight of excellence given to their use of their body to problem themselves around a track and their ability to exploit technical aids. Pistorius and other double amputees should not be competing against athletes with a single amputation for the same reason that Pistorius should not be able to compete against able-bodied athletes. The balance of excellences when they run is different. They are effectively competing in different sports, and as a result the same sanctions should be applied to the Paralympics as I recommended for Pistorius at the Olympics. Single and double amputees should be separated.

Concluding that Pistorius should not be allowed to compete against ablebodied athletes, but also that he should not be allowed to compete against single amputee athletes is not just problematic for him. There are also consequences for all double amputee athletes, and all single amputee athletes for that matter. The reason is for this is numbers. Or lack of numbers to be precise. In the introduction of this essay I discussed the possibility of Pistorius being the first of many amputee athletes with the potential to cross over to able-bodied events. This is down to the increasing numbers of fit young people having their legs blown off in Iraq and Afghanistan, and the advances in battlefield medical treatments. However, these numbers have not increased to the point whereby double amputees or single amputees to justify having their own events. Only five T43 (double amputee) athletes entered the 400m in London, and seven T44 (single amputee) athletes. Until these numbers improve it is better for the Paralympics if they combine the two categories, rather than have an event that three out of the five competitors get a medal

\section{How Do We Solve a Problem Like Pistorius?}

I ended the previous section by stating that even though double and single amputee athletes are not comparable when they run they should still compete against each other until they have enough numbers for stand alone events. 
However, if this is to be the case then something must change in order to make their performances comparable. This is not a change in the sense of a change to redress the balance of excellences, but a change in the system of measuring their performances so that those different excellences can be compared. I will spend the final section addressing is how we might measure Pistorius' performances if he is to compete against those whom he is different to. I will argue that we can adopt methods that already exist in the Paralympics for measuring the performances of differently abled competitors in order to compare what would otherwise be incomparable. I will conclude that while such a system could be adopted to allow Pistorius to compete at the Olympics, it should only be seen as a last resort to be used where athletes have nowhere else to compete. It is also a system that is better suited to the Paralympics because measuring athletes using different systems in the same event would change the nature of the Olympics, but it is a practice that is already firmly entrenched in the Paralympics.

If Pistorius is to compete against others how should we measure his performances? S. D. Edwards points out that if we are obliged to let Pistorius compete there is a case for implementing some sort of handicapping system so that Pistorius and others can compete on a level playing field. However, he concludes that any such system would be doomed to failure. Edwards starts by pointing out that no two competitors are identical therefore if we were to make adjustments for Pistorius, we would presumably have to do the same for all athletes and assign them different handicaps. He then concludes that to do this would lead to farcical results. He imagines a system whereby competitors start a different distance from the finish line based on their ability to finish the race the fastest, with the least equipped starting "perhaps a metre or less from the finish line" (2008, pp. 121-123). Certainly such an approach would be farcical. This is because, as I have explained in depth, the importance of making sure competitors are competing in the same sport. By altering the distance in a race the sport is certainly being altered. By definition a 400m race should not be run over $254 \mathrm{~m}$, regardless of how impaired a competitor is. 
Athletes with different levels of impairment competing against each other are nothing new. It is quite a common phenomenon at the Paralympics: swimming in particular often sees athletes with a variety of different disabilities competing against each other in the pool due to a lack of competition from those with the same disability. This does not mean that they are each competing in their own category and several medals are handed out after each race to the winners in each disability category. All the differentlyabled swimmers are competing for a single set of medals. The differentlyabled swimmers who compete against each other are timed differently using a points system.

The points system is a rather simple and ingenious way of measuring athletes with different abilities against each other. Each swimmer competing is assigned a class according to their disability and event, just as Pistorius is a T43 and single amputee runners are T44. They are then measured against the world record time in their class for the event they are competing in. So if a swimmer wins the race by a clear margin but is five seconds short of the world record in their class they will lose to a swimmer who is three seconds short of the world record in their own particular class. The swimmer who wins the race will not necessarily be the swimmer who finishes a race first.

A similar system of measurement could be applied to Pistorius when he competes against others who do not share his status as a double below the knee amputee. If Pistorius (and other double amputees) is measured against the world records in the T43 class as opposed to being directly measured against T44 athletes it would not be a fairer way of assessing all involved. For an example of how it would be fairer one only needs to look at the T44/43 200m final in London where a South African amputee set a new world record. The name of the record setter was not Oscar Pistorius; it was Arnu Fourie. Unfortunately for Fourie his world record was set in the T44 class and there were three $\mathrm{T} 43$ athletes in the race who were faster than him and he finished fourth. If a points system were adopted similar to the one used in Paralympic swimming Fourie would have taken home the gold medal. 
One of the great things about athletics is that you get results quickly. When the athletes cross the line you more-or-less know the result. You get to see the thrill of an athlete getting over taken in the home straight. If athletics were to adopt the world record relative points based system I have discussed, this visceral thrill risks being removed from running. As this seems to be one of the key factors that attracts fans to the sport there is a strong argument that it should be retained with the spectators best interests in mind. There are, of course, very exciting occasions where the results are delayed. There are few moments tenser than the seconds that pass after a race that is decided by a photo finish. So rather than depleting the spectacle perhaps this new scoring system would add to it as a crowd tensely waits for the calculation of who is the winner. Though this seems unlikely, and I think the explanation for the excitement of a photo finish can be explained by the Sports Incongruity Theory described earlier. Over time it would likely get tedious.

There might be ways around the delay in knowing who won. Once again it is an innovation that comes from swimming. Those who watched the Olympic Games in London will have noticed that at the conclusion of swimming events a computer generated yellow line would start moving across the pool. This line signified the current world record time, and offered a guide as to whether the World Record was likely to be beaten. If a swimmer was ahead of the line then it indicated they were swimming inside the current world record time. If a similar system were adopted it would offer viewers a guide as to how close each runner was to their respective world record time, and thus winning the race.

It might all be too confusing and convoluted to take off. Nevertheless, it is something worth considering if double and single amputee athletes are to continue competing against each other. One last thing to consider is whether such a system could be adopted to allow Pistorius to compete at the Olympics. If the system that I have argued can make the incomparable comparable then it could be a way around Pistorius tipping the balance of excellences of $400 \mathrm{~m}$ running. The reason that this system is better suited to the Paralympics than the Olympics is that similar systems already exist in other Paralympic events. 
I have spoken at length in this essay about the importance of maintaining the integrity of sporting competitions. The Olympic Games is not an event where competitors compete against each other but are measured according to different systems. The Paralympics is such an event; its categorisation system is a key part of its existence. While there are events at the Olympics that have different categories, for instance weight categories in boxing, there are no events that have different categories competing against each other. Furthermore, this system is a last resort. It is a way of giving a place to those who have nowhere else to compete. Pistorius does not need to compete against able-bodied athletes as he has the Paralympics where he can compete against those that he is more similar to him. While he is not comparable to T44 athletes, he is more comparable to them as he is to able-bodied athletes as they excellence of exploiting technical aids plays an important role for both.

\section{Conclusion}

In the first chapter I argued that Pistorius' eligibility for the Olympic Games should be based on whether he is competing in the same sport as able-bodied athletes when he runs. I then established that the best method for deciding whether Pistorius is competing in the same sport as able-bodied athletes is to assess whether he maintains the balance of excellences of Olympic 40om running.

I began this chapter by using two examples from golf to illustrate how the balance of excellences model can be applied to instances of technology threatening to fundamentally alter of a sport. I then established the most basic and uncontroversial excellences of 40om running: to go fast, to use your body to propel yourself, and to exploit technical aids. I defended the inclusion of the exploitation of technical aids on the grounds that it is an excellence in all sports. I then compared 40om running and motor racing to show that it is not just the excellences that are important, but also the balance that those excellences have. I demonstrated that for 40om running in the Olympics, using your body to propel yourself around the track is a dominant excellence. Whereas exploiting technical aids plays a minor role. 
This led to the discussion of whether Pistorius maintains the balance of excellences of Olympic 40om running. I argued that he does not. Using a thought experiment involving Pistorius, Formula 1 world champion Sebastian Vettel, and Olympic 40om champion Kirani James, I displayed that the excellence of exploiting technical aids is far more important for Pistorius than it is for able-bodied runners. Pistorius tips the balance of excellences of $400 \mathrm{~m}$ running in the Olympics. As a result what he does, and what able-bodied athletes do when they run 400m, is very different. They are not competing in the same sport, and the different sports which they compete in are not comparable. I concluded that Oscar Pistorius should not be allowed to compete against able-bodied athletes at the Olympics Games.

I spent the remainder of the chapter discussing the implications of the balance of excellences on Pistorius competing at the Paralympics. As double-amputees compete against single-amputees at the Paralympics I examined whether the two sets of athletes were comparable. I concluded that just as able-bodied runners and double-amputee runners have a different balance of excellences; the same is true of double and single-amputees. Thus Pistorius should not be allowed to compete against single-amputee runners either. However, the two different sets of athletes compete against each other because there are not enough numbers to justify them having their own categories. Therefore, until such a time as there are enough athletes to justify separate categories, I suggested that a different method for measuring them should be adopted. Drawing on a method used in Paralympic swimming for measuring differently-abled athletes against each other, I argued that the incomparable could be made comparable. This can be done by measuring differently categorized runners against the world record times in their own categories as opposed to the traditional first-past-the-post system. Such a system would more fairly reflect the achievements of each set of athletes than comparing them directly to each other. 


\section{Conclusion}

\section{Argument Summary and Implications}

The purpose of this essay was to establish whether or not Oscar Pistorius should be allowed to compete at the Oympic Games. Pistorius is a double below the knee amputee who runs on J-shaped, carbon fibre, blades. In 2012 He became the first runner to compete in athletics at the Olympic Games using prosthetic limbs. Experts in the field of prosthetic technology predict that he is the first of many with the potential to cross over from the Paralympics to the Olympics (Phillip, 2012). This makes Pistorius the perfect case study to use for putting in place guidelines for dealing with improved prosthetic technology which might allow disabled athletes to compete against able-bodied athletes in sport.

I began this essay by establishing that the best method to determine whether Pistorius should be allowed to compete at the Olympics is to decide whether he is competing in the same sport as able-bodied athletes. This is a strategy that takes into account the interests of the competitors, the spectators, and the sport as an end in itself. I then argued that best method for determining whether or not Pistorius is competing in the same sport as able-bodied athletes is John William Devine's (2010) theory that sport is the pursuit of certain excellences, and that the balance of these excellences must be maintained. I explained that the reason Devine's theory is so attractive is that it preserves the nature of sport by ensuring athletes are competing in comparable terms, without preventing progress within a sport.

I used the final chapter of this essay to demonstrate how the balance of excellences can be applied to situations were technology threatens to alter the nature of a sport. I then established that the most basic excellences of Olympic 400m running are: 
1. Going fast

2. Using your body to propel yourself around a trach

3. Exploiting technical aids

I demonstrated that using your body to propel yourself around a track is the dominant excellence in 400m running, with exploiting technical aids playing a minimal role. I argued that Pistorius tips the balance of excellences of $400 \mathrm{~m}$ running too far in favour of exploiting technical aids, and as a result he is not competing in the sport of $400 \mathrm{~m}$ running. Instead he is competing in the sport of T43 40om running. I concluded that he should not be allowed to compete against able-bodied athletes at the Olympic Games, as he is not competing in the same sport that they are.

Moving forward this framework can help assess the eligibility of disabled athletes for able-bodied competition. Not all amputees will upset the balance of excellences of able-bodied competition because not all sports have the same balance of excellences as $400 \mathrm{~m}$ running. If it is applied on a case-by-case basis, the balance of excellences argument can help to preserve key aspects of sport without preventing progress. I have also offered a possible solution for situations where two otherwise incomparable sets of athletes must compete against each other due to lack of alternative competition. Be it on the global stage of the Paralympics, or at a high school track meet. If athletes who are fundamentally different are to compete against each other they should be measured against the world records in their classification. This is an inclusive approach that also deals with the realities that some people cannot be accurately measured against one another.

Oscar Pistorius is a pioneer and an inspiration to many, but this should not blind us to the fact that what he is doing when he runs is fundamentally different to able-bodied athletes. He is a great athlete whose place in sporting history is assured but no one has an unalienable right to compete at the Olympics. There are many sports that are similar to Olympic events that are not currently part of the great sporting spectacle. This does not give other athletes the right to enter events on their own terms. The individual pursuit 
was dropped from the track cycling programme for the 2012 Games. This was unfortunate for New Zealand's world champion pursuiter, Alison Shanks, but it does not give her the right to enter the team pursuit on her own in search of glory. The same is true of Pistorius. While he is not out of place at the Olympic Games, until the T43 400m is included as an Olympic event, he does not have a place there. 


\section{Works Cited}

Agar, N. (2011). Sport, Simulation, and EPO. In N. Agar, The Ideal of Nature: Debates about Biotechnology and the Environment (pp. 149-167). Baltimore, Md: The Johns Hopkins University Press.

Bainbridge, А. (2012 йил 21-February). Prosthetic technology may give Paralympic advantage. Retrieved 2012 йил 16-July from ABC Grandstand Sport: http://www.abc.net.au/news/2012-02-21/prosthetic-technology-maygive-paralympic-advantage $/ 3843638$ ? section=sport

BBC. (2009, March 19). Fina Extends Swimsuit Regulations. Retrieved February 14, 2012 from BBC Sport:

http://news.bbc.co.uk/sport2/hi/olympic_games/7944084.stm

BBC. (2011, December 14). London 2012: Grey-Thompson rejects Games merger calls. Retrieved January 4, 2012 from BBC: http://news.bbc.co.uk/sport2/hi/olympics/16170796.stm?print=true

BВC. (2006 йил 4-February). Murali cleared by yet more tests. Retrieved 2012 йил 11-July from BBC SPORT:

http://news.bbc.co.uk/sport2/hi/cricket/4680246.stm

Beard, M. (2007, February 10). Injured Iraq veterans recruited to compete in the Paralympics. Retrieved July 4, 2012 from The Independent: http://www.independent.co.uk/sport/olympics/injured-iraq-veteransrecruited-to-compete-in-the-paralympics-435803.html 
Bohannon, R. W. (2007). Number of Pedometer-Assessed Steps Taken Per Day by Adults: A Descriptive Meta-Analysis. Physical Therapy , 87 (12), 16421650.

Charlish, P., \& Riley, S. (2007). Should Oscar Run? Fordham Intellectual Property, Media \& Entertainment Law Journal , 18, 929-957.

Chockalingam, N., Thomas, N. B., Smith, A., \& Dunning, D. (2011). By designing 'blades' for Oscar Pistorius are prosthetists creating an unfair advantage for Pistorius and an uneven playing field? Prosthetics and Orthotics International , 35 (4), 482-483.

Edwards, S. D. (2008). Should Oscar Pistorius be Excluded from the 2008 Olympic Games? Sport, Ethics, and Philosophy , 2 (2), 112-125.

Dugas, J., \& Tucker, R. (2008, January 14). Oscar Pistorius banned by IAAF carbon fibre blades offer "Clear mechanical advantages". Retrieved January 1, 2013 from The Science of Sport:

http://www.sportsscientists.com/2008/01/oscar-pistorius-announcementbanned_14.html

Davidson, T. (2011, 10 10). Performance Enhancing Drugs and the Spirit of Sport . Unpublished Manuscript . Victoria University of Wellington.

Daniels, N. (2000). Normal Functioning and the Treatment-Enhancement Distinction. Cambridge Quarterly of Healthcare Ethics , 9 (3), 309-322.

Devine, J. W. (2010). Doping is a Threat to Sporting Excellence. British Journal of Sports Medicine , 45, 637-639.

Deckers, L., \& Buttram, R. T. (1990). Humor as a response to incongruities within or between Schemata. Humor - International Journal of Humor Research , 3 (1), 53-64. 
International Association of Athletics Federations . (2008). Competition Rules 2008. International Association of Athletics Federations . Monaco: International Association of Athletics Federations .

International Paralympic Committee. (2011). IPC Athletics Classification Rules and Regulations. Bonn, Germany: Internation Paralympic Committee.

Internationall Paralympic Committee. (2012, 11 27). London 2012 Paralympics proves a worldwide TV ratings winner . Retrieved 12 29, 2012 from International Paralympic Committee:

http://www.paralympic.org/press-release/london-2012-paralympics-provesworldwide-tv-ratings-winner

Hamilton, M. (2006). Elective Performance Enhancing Surgery for Athletes: Should it be Resisted? Acta Universitatis Palackianae Olomucensis Gymnica , $36(2), 39-46$.

Jones, C., \& Wilson, C. (2009). Defining Advantage and Athletic Performance: The Case of Oscar Pistorius. European Journal of Sport Science , 9 (2), 125131.

Kessel, A. (2012, May 24). Oscar Pistorius defends his participation in London 2012 Olympics. Retrieved January 1, 2013 from The Guardian: http://www.guardian.co.uk/sport/2012/may/24/oscar-pistorius-london2012-olympics

Kram, R., Grabowski, A. M., McGowan, C. P., Brown, M. B., \& Herr, H. M. (2010). Counterpoint: Artificial Limbs do not make Artificially Fast Running Speeds Posible. Journal of Applied Physiology , 108, 1012-1014.

Norman, M. E., \& Moola, F. (2011). 'Bladerunner or Boundary Runner'?: Oscar Pistorius, Cyborg Transgressions and Strategies of Containment. Sport in Society , 14 (9), 1265-1279. 
Perry, C. (1983). Blood Doping and Athletic Competition. International Journal of Applied Philosophy , 1 (3), 39-45.

Phillip, R. (2012, January 29). Oscar 'Could be Fastest Man' . Retrieved February 2, 2012 from Times LIVE:

http://www.timeslive.co.za/local/2012/o1/29/oscar-could-be-fastest-man

Suits, B. (1978). The Grasshopper: Games, Life and Utopia. Toronto: University of Toronto Press.

Silvers, A., \& Wasserman, D. (2000). Convention and competence: Disability rights in sports and education. Society , 37 (3), 63-67.

Sokolove, M. (2012, January 18). The Fast Life of Oscar Pistorius . Retrieved January 19, 2012 from New York Times:

http://www.nytimes.com/2012/01/22/magazine/oscarpistorius.html?pagewanted $=1 \& \_r=3$

The Telegraph. (2007, July 4). The greatest goals of all time. Retrieved December 28, 2012 from The Telegraph:

http://www.telegraph.co.uk/sport/2317065/The-greatest-goals-of-alltime.html

United Nations. (2006). Convention on the Rights of Persons with Disabilites. New York: United Nations.

Wasserman, D. (2008). Performance-Enhancing Technologies and the Values of Athletic Competition. Philosophy \& Public Policy Quarterly , 28 (3), 22-27.

Weyand, P. G., \& Bundle, M. W. (2009). Point: Artificial Limbs do make Artificially Fast Running Speeds Posible. Journal of Applied Physiology , 108, 1011-1012. 
Weyand, P. G., Bundle, M. W., McGowan, C. P., Grabowski, A., Brown, M. B., Kram, R., et al. (2009). The Fastest Runner on Artificial Legs: Different Limbs, Similar Function? The Journal of Applied Physiology , 107 (3), 903911.

Wolbring, G. (2008). Oscar Pistorius and the Future Nature of Olympic, Paralympic and Other Sports. Scripted - A Journal of Law, Technology \& Society , 5 (1), 139-160.

World Anti-Doping Agency. (2003). World Anti-Doping Code. Montreal: World Anti-Doping Agency .

van Hilvoorde, I., \& Landeweerd, L. (2008). Disability or Extraordinary Talent-Francesco Lentini (Three Legs) Versus Oscar Pistorius (No Legs). Sport, Ethics and Philosophy , 2 (2), 97-111. 